\title{
Phylogenetics and the evolution of major structural characters in the giant genus Euphorbia L. (Euphorbiaceae)
}

\author{
James W. Horn a , Benjamin W. van Ee ${ }^{b}$, Jeffery J. Morawetz ${ }^{c}$, Ricarda Riina ${ }^{\text {d,e }}$, Victor W. Steinmann ${ }^{f}$, \\ Paul E. Berry ${ }^{\mathrm{d}}$, Kenneth J. Wurdack ${ }^{\mathrm{a}, *}$ \\ a Department of Botany, Smithsonian Institution, NMNH MRC-166, P.O. Box 37012, Washington, DC 20013-7012, USA \\ ${ }^{\mathrm{b}}$ Black Hills State University Herbarium, 1200 University St., Spearfish, SD 57799, USA \\ ${ }^{\mathrm{c}}$ Rancho Santa Ana Botanic Garden, 1500 North College Ave., Claremont, CA 91711-3157, USA \\ d Department of Ecology and Evolutionary Biology, and University of Michigan Herbarium, 3600 Varsity Dr., Ann Arbor, MI 48108-2287, USA \\ e Real Jardín Botánico, CSIC, Plaza de Murillo 2, 28014 Madrid, Spain \\ f Instituto de Ecología, A.C., Centro Regional del Bajío, A.P. 386, 61600 Pátzcuaro, Michoacán, Mexico
}

\section{A R T I C L E I N F O}

Article history:

Received 13 July 2011

Revised 17 November 2011

Accepted 28 December 2011

Available online 21 January 2012

\section{Keywords:}

Character state reconstruction

Convergent evolution

Cyathium

Euphorbia

Growth form

Multigene analyses

Xerophyte

\begin{abstract}
A B S T R A C T
Euphorbia is among the largest genera of angiosperms, with about 2000 species that are renowned for their remarkably diverse growth forms. To clarify phylogenetic relationships in the genus, we used maximum likelihood, Bayesian, and parsimony analyses of DNA sequence data from 10 markers representing all three plant genomes, averaging more than $16 \mathrm{kbp}$ for each accession. Taxon sampling included 176 representatives from Euphorbioideae (including 161 of Euphorbia). Analyses of these data robustly resolve a backbone topology of four major, subgeneric clades-Esula, Rhizanthium, Euphorbia, and Chamaesyce-that are successively sister lineages. Ancestral state reconstructions of six reproductive and growth form characters indicate that the earliest Euphorbia species were likely woody, non-succulent plants with helically arranged leaves and 5-glanded cyathia in terminal inflorescences. The highly modified growth forms and reproductive features in Euphorbia have independent origins within the subgeneric clades. Examples of extreme parallelism in trait evolution include at least 14 origins of xeromorphic growth forms and at least 13 origins of seed caruncles. The evolution of growth form and inflorescence position are significantly correlated, and a pathway of evolutionary transitions is supported that has implications for the evolution of Euphorbia xerophytes of large stature. Such xerophytes total more than 400 species and are dominants of vegetation types throughout much of arid Africa and Madagascar.
\end{abstract} Published by Elsevier Inc.

\section{Introduction}

Euphorbia L. sensu lato (Euphorbiaceae), with close to 2000 currently recognized species and a nearly global distribution, is among the largest of the "giant genera" of flowering plants (Govaerts et al., 2000; Frodin, 2004). Unlike most other large angiosperm clades recognized as genera, species richness in Euphorbia is coupled with remarkable structural variability (Figs. 1 and 2). The combination of these attributes distinguishes the genus as a promising group in which to investigate fundamental evolutionary questions about the origin of morphological novelty and diversification. An understanding of the evolution of reproductive and vegetative traits that encompass the most striking structural variants for which Euphorbia is renowned is necessary to achieve this goal. Hence, our primary objective in presenting a new phylogenetic hypothesis of

\footnotetext{
* Corresponding author.

E-mail address: wurdackk@si.edu (K.J. Wurdack).
}

Euphorbia is to use it as framework for a series of evolutionary analyses that illuminate the origin and evolution of the kaleidoscopic structural diversity within the entire clade. We discuss the biological significance of these results, and comment on their possible significance to the diversification of Euphorbia. Although we do not explicitly test the effect of trait origin on diversification, our results provide a reasonable basis with which to develop two such hypotheses, which will be addressed in future studies.

Variation in reproductive traits within Euphorbia mostly involves characteristics of the inflorescences and the seeds. Euphorbia has a specialized inflorescence type, the cyathium (Fig. 1a), that mimics a flower by clustering reduced male and female flowers within a cup-shaped involucre formed from the bracts associated with groups of male flowers (Hoppe and Uhlarz, 1982; Prenner and Rudall, 2007; Prenner et al., 2008). The cyathium has been invoked as the key innovation that drove the spectacular diversification of the clade, because its origin supposedly enabled a shift from wind pollination in close relatives with catkin-like inflorescences to insect pollination (Croizat, 1937; 

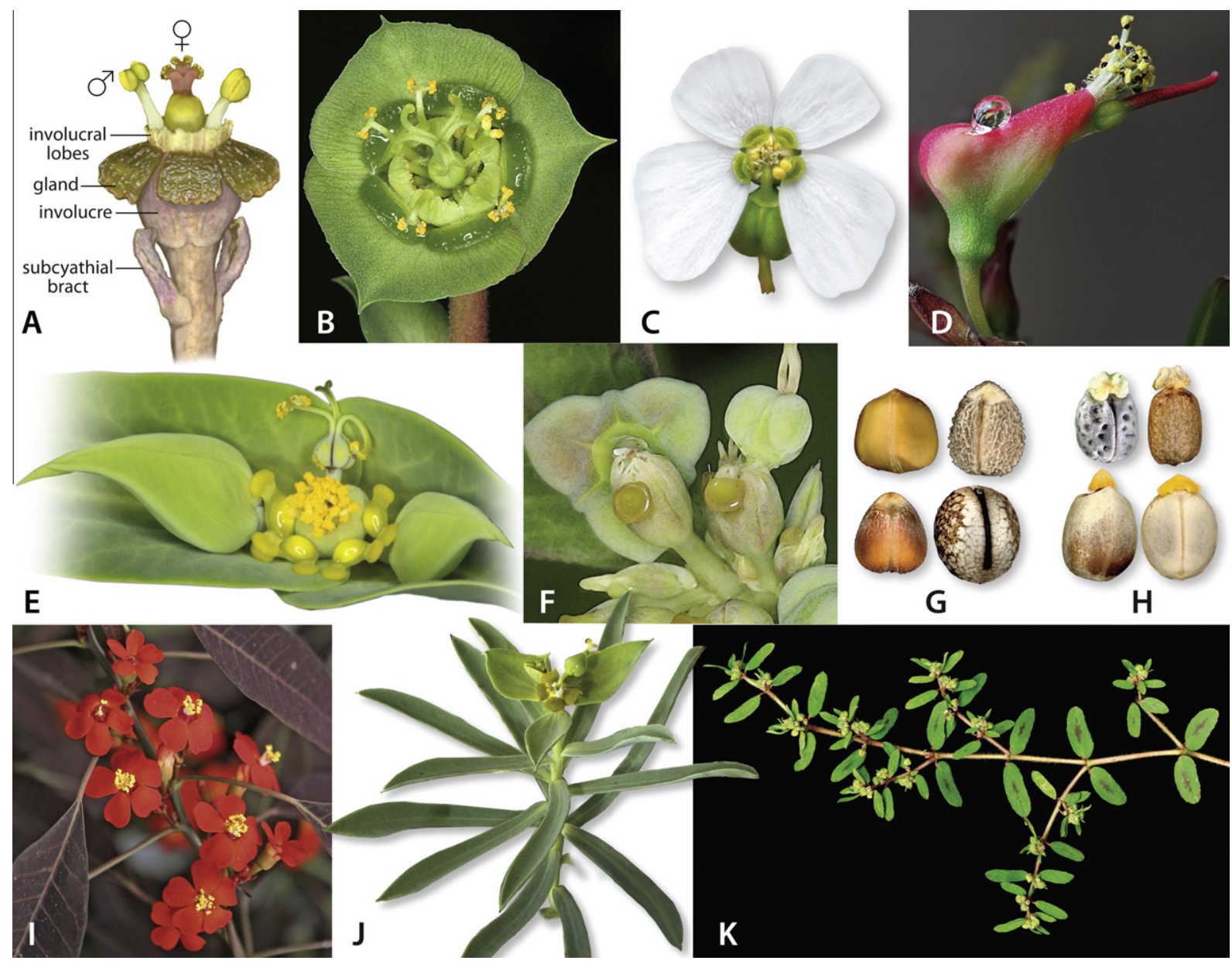

G

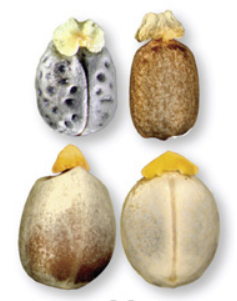

H

Fig. 1. Cyathial, seed, and leaf position characters in Euphorbia. (A) Cyathium of E. fasciculata (Clade A), with main features labeled. (B) Top view of cyathium of E. clava (Clade A), with five dark green unappendaged glands and three lighter green subtending bracts or cyathophylls. (C) Cyathium of E. tamanduana (Clade D; sect. Anisophyllum), with four green glands each bearing a large white petaloid appendage. (D) Cyathium of E. tithymaloides subsp. padifolia (Clade C; sect. Crepidaria), showing bilateral symmetry and nectar drop emerging from hidden involucral glands. (E) Dichasium of E. lathyris (Clade B) showing a central, open cyathium flanked by two unopened cymes and with two open subcyathial bracts behind it. The cyathium has four elliptic glands each with two knob-like appendages. (F) Two cyathia of $E$. heterophylla (Clade D; sect. Poinsettia), showing a single cupulate gland on the edge of each involucre. (G) Ecarunculate seeds (clockwise from upper left; not to scale, all clade A except third): E. dregeana, E. clandestina, E. breviarticulata (Clade C), E. bubalina. (H) Carunculate seeds (clockwise from upper left; not to scale): E. commutata (Clade B), E. nicaeensis (Clade B), E. espinosa (ventral and dorsal views, Clade D). (I) Alternate leaves and terminal cyathium of E. minuta (Clade B). (J) Alternate leaves and axillary cyathia of $E$. fulgens (Clade D; sect. Alectoroctonum). (K) Opposite leaves of E. maculata (Clade D; sect. Anisophyllum). Credits: A. Moller and K. Elliot (A), P. Berry (B, E, I, J), R. Riina (C, F), N. Cacho (D), B. Wagner and K. Elliot (G, H), K. Wurdack (K).

Webster, 1967). The principal structures involved in attracting pollinators in most Euphorbia species are a series of nectary glands positioned at the rim of the cyathial involucre (Fig. 1a). Differences in the merosity of this whorl of glands are readily characterizable among species, and modifications in gland number can confer either positional or constitutional bilateral symmetry to orient pollinators. The cyathial glands often bear appendages, which despite their uniform early ontogeny (Hoppe, 1985) are diverse in shape and size at maturity. These appendages can further enhance the attractive function of the glands by increasing their visibility. Cyathia of several Euphorbia species have gland appendages with a showy, petaloid appearance, and can superficially appear almost indistinguishable from a typical eudicot flower (Fig. 1i). Among the many seed traits that vary in Euphorbia, the presence or absence of a caruncle that functions as an elaiosome is significant because of its potential role in mediating secondary ant dispersal and in its prior use in Euphorbia classification.

The broad array of growth forms within Euphorbia has been well documented, but corresponding ideas and knowledge about the origin and evolution of these varied growth forms is limited. Habit in Euphorbia ranges from small, annual herbs to large trees, but the genus is best known for its great diversity of xeromorphic growth forms that are marked by the presence of tremendous variability in stem succulence (White et al., 1941; Rauh, 1995, 1998). A plant architectural perspective also reflects these perceptions of considerable structural variability. The synoptic survey of Hallé et al. (1978), building on Cremers' (1977) analysis of Madagascan species, established that species of Euphorbia conform to 12 of the 23 recognized architectural models, which is more than any other genus of seed plants.

The four main molecular phylogenetic studies of Euphorbia to date have addressed the overall phylogeny of the genus, with a major point of consensus being the recognition of four subgeneric clades: Rhizanthium, Esula, Euphorbia, and Chamaesyce (Steinmann and Porter, 2002; Bruyns et al., 2006; Park and Jansen, 2007; Zimmermann et al., 2010). Subgenus Rhizanthium (Clade A of Steinmann and Porter, 2002; around 200 spp.) has a primarily African distribution, with most of the species comprising a southern African radiation of xerophytes that are physiognomically diverse. Subgenus Esula (Clade B; around 500 spp.) contains predominantly herbaceous species distributed in the temperate Northern Hemisphere, especially from the eastern Mediterranean through central 

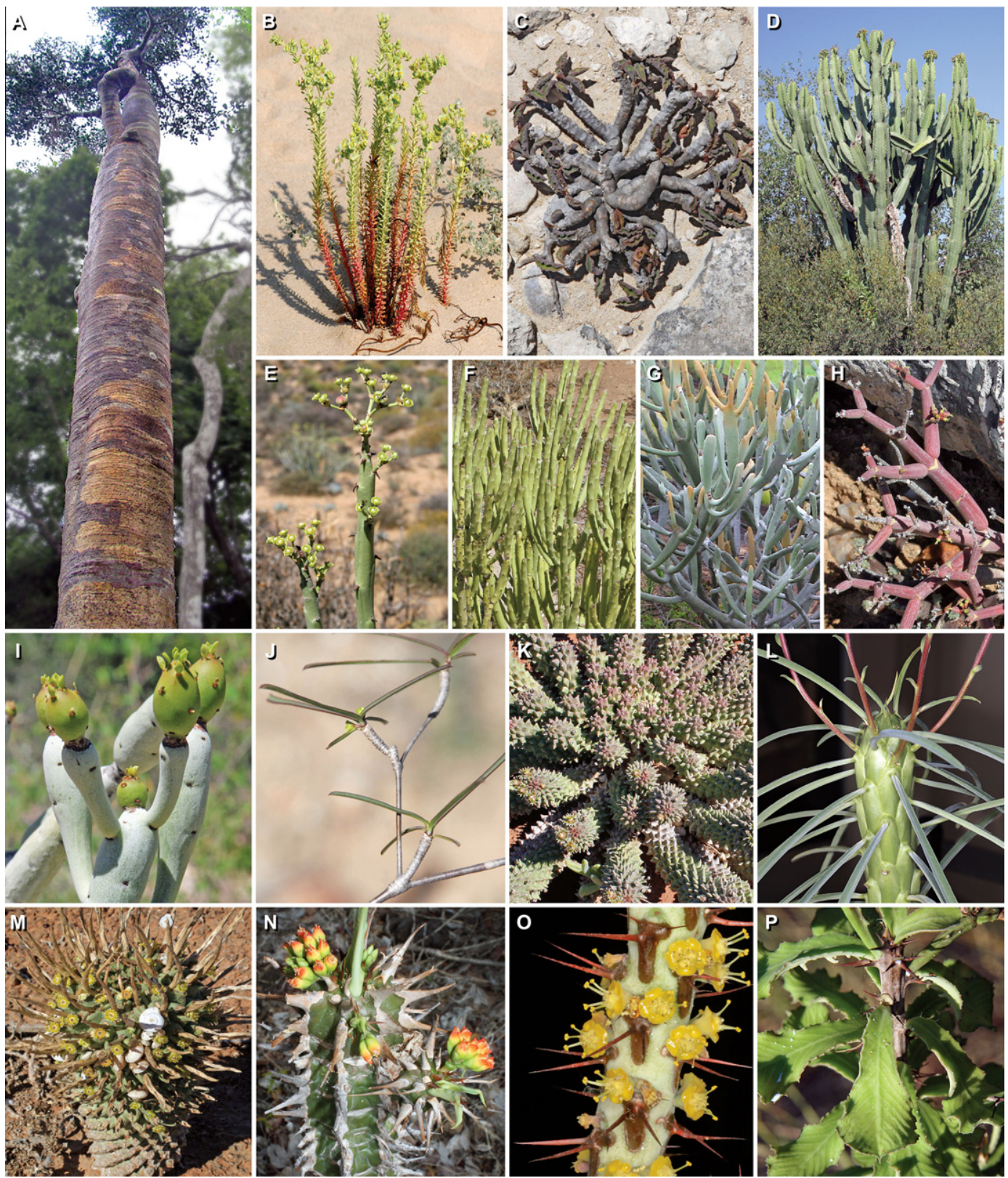

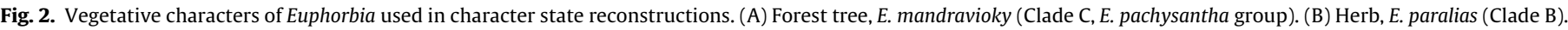

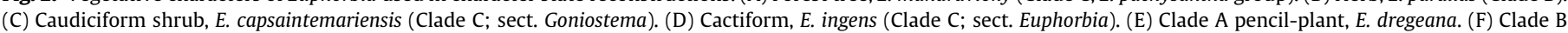

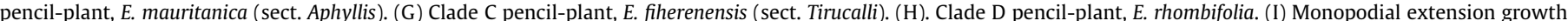

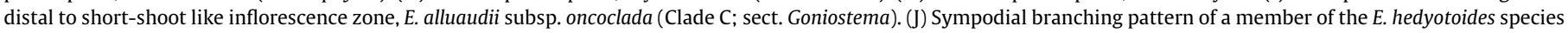

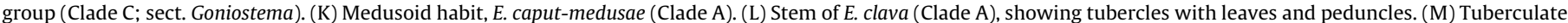

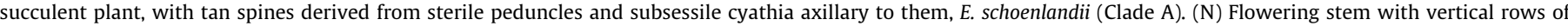

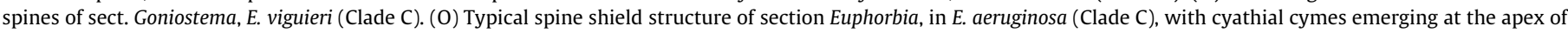
several spine shields. (P). E. neospinescens (Clade C; sect. Monadenium). Credits: L. Gautier (A), J. Molero (B), B. Dorsey (C), P. Berry (D-N), A. Moller (O), J. Morawetz (P).

Asia; but outside of this range (e.g., Macaronesia and Africa) they may be woody plants of tree stature or stem succulents (Molero et al., 2002; Barres et al., 2011). Subgenus Euphorbia (Clade C; around 700 spp.) exhibits the greatest diversity of the four subgeneric clades in both species richness and growth forms. Highlights of its diversity include three major radiations of xerophytes in Africa and Madagascar (Bally, 1961; Carter, 1994; Haevermans, 2003; Haevermans et al., 2004), in addition to a structurally variable Neotropical component. Subgenus Chamaesyce (Clade D; around 600 spp.) contains the majority of New World Euphorbia species. This clade includes a sizeable lineage of around 350 species of mostly
$\mathrm{C}_{4}$ photosynthetic herbs and subshrubs, formerly recognized as the genus Chamaesyce (Webster, 1967; Webster et al., 1975), in addition to the wholly New World core group of the "Agaloma alliance" (Steinmann and Porter, 2002), with around 160 spp., including E. pulcherrima, the familiar Christmas poinsettia. It also includes several relatively species-poor lineages that are mostly found in Africa and Madagascar.

Contemporary knowledge of Euphorbia phylogenetics provides the basis for ongoing revisions to the classification of the genus and indicates that previously recognized segregate genera-including Chamaesyce, Cubanthus, Elaeophorbia, Endadenium, Monadenium, 
Pedilanthus, Poinsettia, and Synadenium, among others-are nested within Euphorbia (Steinmann and Porter, 2002; Steinmann, 2003; Bruyns et al., 2006; Steinmann et al., 2007). Even so, the deeper relationships within the genus remain unclear. Importantly, several hypotheses exist as to the relationships among the four subgeneric clades, and the relationships of major subclades within each of the subgenera are even more ambiguous. The results of previous studies establish three hypotheses of relationships among the subgenera, which are: (1) $((A, B)(C, D))$, recovered by Steinmann and Porter (2002; ITS, $n d h F$, parsimony), Wurdack et al. (2005; rbcL, parsimony and Bayesian), and Steinmann et al. (2007; combined ITS $+n d h F$, likelihood); (2) ( $A(B(C, D))$ ), recovered by Bruyns et al. (2006; ITS, Bayesian) and Zimmermann et al. (2010; ITS, Bayesian); and (3) $(B(A(C, D)))$, recovered by Bruyns et al. (2006; ITS, parsimony), Park and Jansen (2007; $n d h F$, parsimony), Wurdack et al. (2005; trnL-F and combined $t r n L-F+r b c L$, parsimony and Bayesian), and Zimmermann et al. (2010; combined ITS + trnL-F, Bayesian).

Here, we develop a global phylogeny for Euphorbia and closely related genera in tribe Euphorbieae using DNA sequence data from 10 genetic markers spanning all three plant genomes to address this phylogenetic uncertainty and advance Euphorbia phylogenetics. With this new phylogenetic hypothesis for the genus, we provide an evolutionary analysis of major structural traits significant to the biology and classification of Euphorbia using ancestral state reconstructions and hypothesis tests. Specifically, we address: (1) the evolution of cyathial gland merosity; (2) the origin and evolution of cyathial gland appendages; (3) the evolution of caruncles; and (4) the origin and evolution of highly modified growth forms within Euphorbia. Our approach to the last and most complex of these topics involves an analysis not only of growth form per se, but also inflorescence position and phyllotaxy. These are key variables in the architecture of Euphorbia, and character state transitions of these traits appear to be critical to the evolution of the distinctive growth forms within the genus. For instance, we estimate that about $75 \%$ of the approximately 850 strongly xeromorphic Euphorbia species (Carter and Eggli, 2003) have lateral inflorescences, whereas the large majority of non-xeromorphic species have leafy shoots that terminate in an inflorescence. Hence, we test a hypothesis of correlated evolution between these two characters and, further, analyze the sequence of evolutionary transitions using both maximum likelihood and Bayesian-based approaches to correlation and contingency analyses.

\section{Materials and methods}

\subsection{Taxonomic sampling for phylogenetic and comparative analyses}

Our sampling contains 176 terminals, of which 161 belong to Euphorbia sensu lato (i.e., Euphorbia + segregates). Voucher information and GenBank accession numbers for all sequences are provided in Supplementary Table S1. We sampled the commonly recognized segregate genera (i.e., Chamaesyce, Cubanthus, Elaeophorbia, Monadenium, Pedilanthus, Poinsettia, and Synadenium), with the exception of Endadenium. Our Euphorbia sampling is informed by the studies of Steinmann and Porter (2002), Haevermans et al. (2004), Bruyns et al. (2006), and, especially, the emerging results of ongoing phylogenetic studies within each subgenus conducted by the Euphorbia Planetary Biodiversity Inventory (PBI) project (http://www.euphorbiaceae.org/). This information enabled us to include samples from all of the known major lineages within Euphorbia. Outgroups were selected based on the familywide phylogeny of Wurdack et al. (2005) and include the remaining four genera of Euphorbioideae tribe Euphorbieae, in addition to exemplars from all major lineages of the subfamily. We used Nealchornea, a member of Euphorbioideae tribe Stomatocalyceae, to root the topology because Wurdack et al. (2005) placed this tribe sister to the rest of the subfamily. Preliminary analyses using further removed Euphorbiaceae outgroups did not improve the results and greatly increased alignment ambiguity.

Our sampling strategy also took into account the character state distributions for the six characters we investigated with ancestral state reconstructions (see Section 2.5) such that additional sampling would provide little effective information to change significantly our overall results. In an investigation of the effects of taxon sampling density on ancestral state estimation, Salisbury and Kim (2001) suggested that estimates of ancestral states are generally robust to sampling schemes that incorporate the total depth of changes across a given topology. Despite the fact that we sampled about $7.4 \%$ of the total species diversity in Euphorbia, our sampling scheme attempted to cover trait diversity throughout the depth of the tree to the full extent of current knowledge of these six characters. Furthermore, trait diversity is fully represented within our sampling of the outgroup genera of tribe Euphorbieae.

\subsection{Laboratory methods for molecular data}

Our choice of genetic markers was based in part on their demonstrated phylogenetic utility within either Euphorbia or other taxa of Malpighiales. We used 10 markers, spanning all three genomic compartments. Among these were the two markers most frequently used to infer species-level relationships within the genus, nuclear ribosomal ITS and plastid $n d h F$ (Steinmann and Porter, 2002; Park and Jansen, 2007; Steinmann et al., 2007; Zimmermann et al., 2010), as well as data from the plastid markers $r b c L, r b c L-$ $a c c D$ (intergenic spacer and about $1000 \mathrm{bp}$ of the $5^{\prime}$ end of $a c c D$ ), rpl16 (mostly intron), and trnL-F (trnL intron and trnL-F intergenic spacer); the mitochondrial markers nad1B-C (mostly intron; =nad1i477) and rps3 (exon 2); and exons 9 and 12 of the low-copy nuclear gene EMB2765 (Wurdack and Davis, 2009). Exon 12 of $E M B 2765$ is newly used in this study for phylogenetic reconstruction. We largely treated it as a separate marker from exon 9 for the purposes of comparing informativeness, and identifying incongruence that could indicate laboratory or paralogy problems. Multiple divergent copies of exon 9 have been recovered for some species of Euphorbia section Anisophyllum (Yang and Berry, 2011), but most of our accessions yielded clean data for both exons by direct sequencing of their respective amplification products.

Our methods for DNA extraction, amplification, and sequencing for the newly generated data (1511 sequences, totalling $2.0 \mathrm{Mb}$ ) follow those of Steinmann and Porter (2002), Wurdack et al. (2004, 2005), and Wurdack and Davis (2009). Supplementary Table S2 summarizes the primers used for amplification and sequencing. Amplification of exon 12 of EMB2765 followed the same protocol described for exon 9 of this gene in Wurdack and Davis (2009).

\subsection{Sequence and data set assembly}

Sequences were assembled and edited in Sequencher ver. 4.5 (Gene Codes, Ann Arbor, Michigan, USA). No indels were present in exons 9 and 12 of EMB2765 and $r b c L$, but among the remaining markers indel content and alignment ambiguity varied considerably. Alignment complexity was greatest for trnL-F and rpl16. Alignments were performed using MAFFT ver. 5 (Katoh et al., 2005) with default settings followed by manual refinement using Se-Al ver. 2.0a11 (Rambaut, 1996-2002), with a similarity criterion (Simmons, 2004) or using codon positions where appropriate. Indel hotspots were not fragmented to separate overlapping indels. Sites were excluded from regions of ambiguous alignment or that were present in fewer than four taxa. The aligned, combined matrix with 
Table 1

Data set and tree characteristics for Euphorbia phylogenetic analyses.

\begin{tabular}{|c|c|c|c|c|c|c|c|}
\hline Data set & cp $a c c D$ & \multicolumn{2}{|c|}{ cp $r b c L-a c c D$ spacer } & cp $n d h F$ & cp $r b c L$ & ср rpl16 & cp $t r n L-F$ \\
\hline No. terminals & 168 & \multicolumn{2}{|l|}{169} & 165 & 174 & 171 & 168 \\
\hline Aligned length, nt & 2117 & \multicolumn{2}{|l|}{1593} & 1648 & 1377 & 2531 & 1812 \\
\hline Characters analyzed, nt & 980 & \multicolumn{2}{|l|}{604} & 1498 & 1377 & 873 & 926 \\
\hline$\%$ Missing/total missing and ambiguous data & $1.6 / 1.9$ & \multicolumn{2}{|l|}{$2.8 / 4.2$} & $1.1 / 1.4$ & $0.8 / 0.8$ & $1.4 / 2.3$ & $1.9 / 7.7$ \\
\hline Constant characters, nt & 420 & \multicolumn{2}{|l|}{214} & 756 & 1006 & 382 & 449 \\
\hline Variable characters, nt & 560 & \multicolumn{2}{|l|}{390} & 742 & 371 & 491 & 477 \\
\hline Informative characters, nt & 354 & \multicolumn{2}{|l|}{261} & 531 & 219 & 349 & 330 \\
\hline No. MP trees & 324 & \multicolumn{2}{|l|}{$>100000$} & 95 & $>100000$ & 1800 & $>100000$ \\
\hline MP tree length (length excluding uninformative sites) & $1298(1063)$ & \multicolumn{2}{|l|}{$981(830)$} & 2237 (1997) & $960(797)$ & $1473(1305)$ & $1208(1032)$ \\
\hline $\mathrm{CI}$ (CI excluding uninformative sites) & $0.607(0.520)$ & \multicolumn{2}{|c|}{$0.598(0.525)$} & $0.505(0.445)$ & $0.484(0.379)$ & $0.526(0.465)$ & $0.596(0.527)$ \\
\hline RI & 0.848 & 0.853 & & 841 & 0.813 & 0.842 & 0.889 \\
\hline Data set & mt nad $1 B-C$ & $\mathrm{mt} r p s 3$ & $\begin{array}{l}\text { nu } E M B 2765 \\
\text { exon } 9\end{array}$ & $\begin{array}{l}\text { nu } E M B 2765 \\
\text { exon } 12\end{array}$ & $\begin{array}{l}\text { nu EMB2765 } \\
\text { exons } 9 \& 12\end{array}$ & nu ITS & $\begin{array}{l}\text { combined total } \\
\text { evidence }\end{array}$ \\
\hline No. terminals & 172 & 174 & 169 & 161 & 174 & 176 & 176 \\
\hline Aligned length, nt & 1785 & 1644 & 819 & 942 & 1861 & 742 & 17,010 \\
\hline Characters analyzed, nt & 1474 & 1467 & 819 & 942 & 1861 & 555 & 11,515 \\
\hline$\%$ Missing/total missing and ambiguous data & $3.3 / 8.0$ & $1.1 / 2.9$ & $2.4 / 2.4$ & $1.9 / 1.9$ & $2.0 / 2.0$ & $0.3 / 1.8$ & $5.0 / 6.5$ \\
\hline Constant characters, nt & 1088 & 1062 & 429 & 461 & 890 & 149 & 6416 \\
\hline Variable characters, nt & 386 & 405 & 390 & 481 & 871 & 406 & 5099 \\
\hline Informative characters, nt & 179 & 232 & 316 & 370 & 686 & 337 & 3478 \\
\hline No. MP trees & $>100,000$ & $>100,000$ & $>100,000$ & $>100,000$ & $>100,000$ & $>100,000$ & 591 \\
\hline MP tree length (length excluding uninformative sites) & $563(344)$ & $752(569)$ & $1749(1670)$ & $2267(2146)$ & 4079 (3923) & 4076 (3995) & $18,079(16,260)$ \\
\hline $\mathrm{CI}$ ( $\mathrm{CI}$ excluding uninformative sites) & $0.769(0.622)$ & $0.632(0.513)$ & $0.345(0.314)$ & $0.325(0.287)$ & $0.377(0.351)$ & $0.218(0.203)$ & $0.421(0.356)$ \\
\hline RI & 0.923 & 0.903 & 0.766 & 0.752 & 0.767 & 0.703 & 0.794 \\
\hline ML score $(\ln L)$ & - & - & - & - & - & - & -127425.1 \\
\hline
\end{tabular}

details of the excluded regions is archived in TreeBASE (<www. treebase.org/treebase/index.html>).

\subsection{Phylogenetic analyses}

We determined nucleotide substitution models for 11 data partitions (i.e., each of the 10 markers plus the approximately $1000 \mathrm{bp}$ of the $a c c D$ gene) in Modeltest ver. 3.6 (Posada and Crandall, 1998) using the Akaike Information Criterion (AIC; Akaike, 1974). A GTR $+\mathrm{I}+\Gamma$ model was selected for all partitions except the $r b c L-$ $a c c D$ spacer and the $a c c D$ gene, for which the GTR $+\Gamma$ model was the best fit.

Prior to analyzing these data partitions with a "total evidence" approach (Kluge, 1989), we conducted maximum likelihood (ML; Felsenstein, 1973) bootstrap analyses of each partition using GARLI ver. 1.0 (Zwickl, 2006). The bootstrap analyses (Felsenstein, 1985) were executed with 500 pseudoreplicates, each based on two independent search replicates. Model parameters were set in accordance with the results obtained from Modeltest, but these values were not fixed, so that GARLI could optimize them within each search replicate. An automated stopping criterion was used, aborting each search replicate after $1 \times 10^{4}$ generations of a stable $-\ln L$ value. We used the results of these analyses as the basis for assessing topological congruence among the individual marker trees, comparing them in a pairwise manner to identify instances of strongly supported (i.e., with a bootstrap percentage $[\mathrm{BP}] \geqslant 85$ ) topological conflict.

We employed ML, Bayesian, and parsimony approaches for analyzing the concatenated data matrix. ML optimization of the unpartitioned matrix was implemented in GARLI using 100 independent search replicates. Starting parameter values were set to a GTR model, and allowed to be further optimized within each replicate. We enforced an automated stopping criterion for each replicate when a stable $-\ln L$ value was attained for $2 \times 10^{4}$ generations. ML bootstrap support values for the concatenated matrix were estimated using 1000 pseudoreplicates, but otherwise following the same search strategy as for the individual partitions. For convenience, we refer to clades with $\geqslant 85 \mathrm{BP}$ as being strongly supported, 84-70 as moderately supported, and 69-50 as poorly supported.

Bayesian MCMC analyses (Yang and Rannala, 1997) were implemented in MrBayes ver. 3.1.2 (Huelsenbeck and Ronquist, 2001; Altekar et al., 2004), with the markers individually partitioned and modeled independently using the results of the model selection tests. Within each partition, default priors were used for the rate matrix, branch lengths, gamma shape parameter (Yang, 1993), and the proportion of invariant sites (where appropriate; Reeves, 1992). A flat Dirichlet distribution was used for the base frequency parameters, and a uniform prior was used for the tree topology. The final analyses were conducted with two concurrent runs of six incrementally heated chains for $5 \times 10^{7}$ generations that were sampled every 100 generations, with the temperature coefficient set to 0.5 to promote adequate mixing between the chains. The program AWTY (Wilgenbusch et al., 2004; Nylander et al., 2008) was used to diagnose topological convergence, with emphasis placed on the results of the Cumulative, Split, and Compare diagnostics. These results indicated a burn-in period of $4.76 \times 10^{7}$ generations, which was much more conservative than the $2.0-2.7 \times 10^{7}$ generations suggested by the plot of the log likelihood values viewed in Tracer ver. 1.5 (Rambaut and Drummond, 2003-2007). Trees from the post burn-in period of each analysis were pooled $\left(4.8 \times 10^{4}\right.$ trees in total $)$ to calculate Bayesian posterior probabilities (PP).

Parsimony analyses were implemented in PAUP* ver. 4.0b10 (Swofford, 2002) following the search strategies of Wurdack and Davis (2009). Uninformative characters were excluded in the analyses, except for calculating alternative tree statistics (Table 1). Bootstrap support was evaluated from 1000 pseudoreplicates, each with five random-addition replicates using the tree-bisectionreconnection (TBR) branch swapping algorithm, holding 10 trees at each step, and without search limits.

To assess whether alternative hypotheses of the backbone relationship of the subgeneric clades within Euphorbia have likelihood scores significantly worse than the topology resolved in the unconstrained ML analysis, we generated constraint trees in GARLI consistent with these hypotheses, and compared them using the 
approximately unbiased test (AU test; Shimodaira, 2002, 2004) in CONSEL ver. 0.1i (Shimodaira and Hasegawa, 2001).

\subsection{Morphological character data}

Characters were primarily scored from herbarium specimens from G, IEB, MA, MICH, P, and US, supplemented by observations of living plants, and secondarily by published descriptive accounts of relevant Euphorbia species.

Character 1: Cyathial gland merosity has three states: (0) five (Fig. 1b), (1) four (Fig. 1c and e), or (2) one to two (Fig. 1f). The cyathial involucre always bears a series of glands around its rim. We scored this character from lateral cyathia, because the cyathium that terminates the inflorescence axis sometimes bears more glands relative to those of the lateral cyathia, or is substantially different in body plan organization, as in E. pulcherrima (Steinmann and Porter, 2002). We grouped gland merosities of one or two into a single character state because species that bear (usually inconsistently) two glands on each cyathium have them restricted to one side of the cyathium, as do most single-glanded species. Moreover, this character state is discontinuous with the state of four glands because there are no known Euphorbia species that consistently bear cyathia with three glands. A few Euphorbia species have cyathia that regularly bear more than five glands (e.g., E. capitulata with eight and E. haeleeleana with up to 11; Croizat, 1936; Herbst, 1971). However, this state does not provide any grouping information given the sampling in this and other studies. Within our sampling scheme, E. macrocarpus is the only species that consistently bears more than five (here, six) glands, and we coded it as inapplicable. We also scored taxa outside of Euphorbia as inapplicable for this character, owing to the often significant differences in inflorescence structure in those groups relative to Euphorbia.

Character 2: Appendages associated with the glands borne on the cyathial involucre are (0) absent (Fig. $1 \mathrm{~b}$ and f), or (1) present (Fig. 1c-e, and i). In the four genera of Euphorbieae outside of Euphorbia, these glands never develop appendages (Prenner and Rudall, 2007; Prenner et al., 2008). In Euphorbia, however, the mature glands of many species are appendiculate with horn- or finger-like appendages along their outer, distal margin (Fig. 1e). Gland appendages may also be petaloid and appear to subtend each gland (Fig. 1c and i). Euphorbia gland appendages may be further elaborated by postgenital fusion to form structural units of diverse function (e.g., the "cap" of the nectar spur in cyathia of section Crepidaria; Fig. 1d). Despite the structural and positional diversity present in Euphorbia gland appendages, Hoppe (1985) demonstrated that they all share a common developmental origin as a lateral outgrowth on each cyathial gland primordium and, on this basis, suggested that they are homologous structures. We restrict our definition of gland appendages to that noted above, but recognize that other, truly appendicular organs associated with Euphorbieae pseudanthia, such as leaves and bracts, can acquire a similar range of functions to those present in the gland appendages (Prenner and Rudall, 2007). We scored taxa outside of Euphorbieae as inapplicable for this character owing to the strongly contrasted positions of their inflorescence glands.

Character 3: A caruncle of the mature seed is: (0) absent (Fig. 1g), or (1) present (Fig. 1h). The caruncle in Euphorbia is a lipid-rich seed appendage that develops adjacent to the micropyle as an outgrowth of the outer integument (Corner, 1976; Carmichael and Selbo, 1999; Tokuoka and Tobe, 2002). In the mature seed, this structure can persist as an elaiosome, but it is absent from many species (Webster, 1967; Ehler, 1976).

Character 4: Growth form has five character states: (0) woody trees or shrubs (Fig. 2a), (1) herbs (Fig. 2b), (2) pencil plants (Fig. 2e-i), (3) cactiform xerophytes (Fig. $2 \mathrm{~d}$, k, and m), or (4) caudiciform shrubs (Fig. 2c). States 0 and 1 describe plants without apparently succulent stems, whereas states 2-4 characterize the strongly xeromorphic growth forms in Euphorbia. The category of woody trees or shrubs distinguishes non-xeromorphic plants without evident, specialized storage capabilities in their stems, whereas herbs contrast with all other states in having aerial shoot systems that are relatively ephemeral. Caudiciform shrubs contrast with other stem succulents in producing a periderm precociously, such that their persistent shoots are soon covered with bark. A delay in periderm production, which enables stems to remain photosynthetically active for many years, distinguishes both pencil plants and cactiform xerophytes. As their name suggests, pencil plants have narrow stem diameters relative to their length, but can also be characterized by lacking stem tubercles. Pencil plants often have aerial shoot systems ramified to several orders and in several planes, such that they can appear densely branched, as in $E$. fiherenensis (Fig. 2g). However, branching in some species of pencil plants is almost exclusively basal, and individual plants grow to be low, caespitose subshrubs comprised of relatively narrow, green stems. Succulence in Euphorbia is most evident in the cactiform xerophytes, which uniformly have pachycaul stems that produce tubercles, a swelling of the tissue of the stem or branch at the base of a leaf (Fig. 2k and m; White et al., 1941). These tubercles, as in cacti, may be helically arranged (Fig. $2 \mathrm{~m}$ ) or vertically superimposed so as to form a series of longitudinal ridges along the stem (Fig. 2d). Euphorbia species with the distinctive "medusoid" growth form (Fig. 2k) were included within this character state.

Character 5: Leaves of the vegetative phase of a shoot are (0) alternate (Fig. 1i and j), or (1) opposite or whorled (Fig. 1k). Opposite leaves may be either decussate or distichous. A description of "mixed" phyllotaxy in many Euphorbia species results from a change in phyllotaxy at the inflorescence boundary, where there is an abrupt transition from alternate to opposite phyllotaxy on account of cymose branching (i.e., exclusively from the axils of prophylls). Prophylls in these species are often laminar (e.g., E. graminea, E. sphaerorhiza).

Character 6: Inflorescences within Euphorbia may be either (0) borne exclusively lateral (axillary) to the persistent shoot system (Fig. 1i), or (1) terminate the axes of the persistent shoot system (Figs. 1j, and 2e). This contrast reflects an important distinction in the branching architecture of Euphorbia between monopodial and sympodial growth. Euphorbia species are not known to conform to plant architectural models in which an indeterminate, monopodial primary axis bears persistent, sympodial lateral branches constructed of modules that terminate in an inflorescence (Cremers, 1977; Hallé et al., 1978). Members of the distinctive E. hedyotoides species group in section Goniostema from Madagascar are exceptional because they can be trees with monopodial trunks, which bear lateral branches that are sympodial by apposition (Fig. 2j). Excluding this group, the distinction we make is applicable at the level of the whole plant among the Euphorbia species we sampled.

\subsection{Ancestral state reconstructions and comparative analyses}

Subsequent to phylogeny estimation, we randomly sampled a set of 1000 trees from the post burn-in period of the Bayesian analysis of the combined matrix in order to account for phylogenetic and branch length uncertainty in all ancestral state reconstructions and hypothesis tests that we conducted. Ancestral state reconstructions were conducted on these trees using ML optimizations (Schulter et al., 1997; Pagel, 1999) for each character in Mesquite ver. 2.74 (Maddison and Maddison, 2006, 2010). To select a model of character evolution for each of the four binary characters, asymmetry likelihood ratio tests were conducted. A one-rate model was selected for characters 2, 5 and 6 (Mk1; Lewis, 2001). A two-rate model was selected for Character 3 (AsymmMk; $P=7.64 \times 10^{-8}-0.3039$, 
$P<0.05$ in 881 of the 1000 trees examined). Optimizations of the two multistate characters used the Mk1 model. A given state was assigned to a node if its raw likelihood was $>2 \log$ units better than the likelihood value(s) of the other states (the default parameter in Mesquite ver. 2.74). The set of reconstructions for each character was then summarized onto the $95 \%$ majority rule consensus tree of all $4.8 \times 10^{4}$ post burn-in trees.

We also tested a hypothesis of correlated evolution between inflorescence position and growth form in Euphorbia. A possible bias in transitions toward xeromorphic growth forms with lateral inflorescences is suggested by the disparity of species richness between the numerous xeromorphic Euphorbia species with lateral inflorescences relative to the much smaller number with terminal inflorescences. Provided that the data rejected a hypothesis of independent evolution of these two characters, we then tested if the eight transition rates between the four, pairwise combinations of character states were significantly unequal or significantly different from zero. In order to apply a binary character-state coding to growth form, we coded the two non-xeromorphic growth forms of Character 4 (see Section 2.5) as state 0 and the three strongly xeromorphic growth forms of Character 4 as state 1 . Our coding of inflorescence position is like that of Character 6 (Section 2.5), but with terminal inflorescences coded as 0 and lateral inflorescences coded as 1 .

The omnibus test for correlated evolution between two binary characters (Pagel, 1994, 1997) was conducted in BayesTraits ver. 1.0 (Pagel and Meade, 2006a) using both Bayesian and ML methods with the set of 1000 trees. Bayesian estimation of the logarithm of the harmonic mean of the likelihood values for the Independent (four-rate) and Dependent (eight-rate) models of evolution were determined with Reverse-Jump MCMC analyses (Pagel and Lutzoni, 2002; Pagel and Meade, 2006b). After initial analyses, we chose to seed the mean and variance of a gamma prior with a uniform hyperprior on an interval of 0-20 (Pagel et al., 2004) and set the ratedev parameter to 1.0 to optimize the rate of proposal acceptance. Final Bayesian analyses of each model were conducted with five independent chains of $1.01 \times 10^{8}$ iterations, sampling the chain every 1000 iterations, and with a conservative burn-in period of $1 \times 10^{6}$ iterations. The five, identical chains run for each analysis allowed us to assess the stability of the logarithm of the harmonic mean of the likelihood values. The logarithm of the harmonic mean from the analysis of each of the models was compared using the Bayes factor test statistic to infer the strength of this evidence for or against correlated evolution. This statistic was calculated from the median values of the log harmonic means of the five identical chains run for both models, which varied less than 0.5 in value from the median value in each of the analyses we describe. A Bayes factor of 5 or greater is interpreted to represent strong evidence for the Dependent model (correlated trait evolution, in the omnibus test), whereas a Bayes factor with a value less than zero is evidence in favor of the Independent model (Kass and Raftery, 1995; Pagel and Meade, 2006a). To assess the probability that the values of each of the eight transition rate parameters of the Dependent model are non-zero, we used the posterior probability distribution of the proportion of evolutionary models visited by the RJ-MCMC chain in which the evolutionary model for each transition rate was assigned a value of zero (Z-score; GonzalezVoyer et al., 2008). Transitions that have a high probability of being non-zero have a $Z$-score $<0.05$. For the ML implementation of the omnibus test, we sequentially calculated the likelihood score for each of the 1000 trees using 100 replicates of the optimization algorithm for both the Dependent and Independent models to obtain the set of likelihood ratios for all 1000 trees. Significance of the likelihood ratio test statistics $(-2 \ln L)$ was assessed against a Chi-square distribution with four degrees of freedom.
Statistical tests in which we constrained one parameter of the Dependent model (Pagel, 1994) used methods like those outlined above, and differed only in using standard MCMC methods for Bayesian analyses (for both the unconstrained and constrained Dependent models) to enable us to constrain two transition rate parameters as equal. Accordingly, $-2 \ln L$ values obtained from ML-based analyses were assessed against a Chi-square distribution with one degree of freedom. The hypotheses we tested against the unconstrained Dependent model were: (1) a series of eight alternative models, in which each of the rate categories was set equal to zero (ML only, complements the Bayesian estimation of these parameters, described above); (2) that transitions from terminal to lateral inflorescences are more likely in strongly xeromorphic lineages than non-xeromorphic lineages $\left(H_{0}: q_{13}=q_{24}\right.$; Fig. 5); and (3) that transitions to a xeromorphic growth form are more likely to precede those to lateral inflorescences $\left(H_{0}: q_{12}=q_{13}\right.$; Fig. 5).

To explore the possible effects of different but, nonetheless, biologically reasonable estimates of branch lengths on our results, we replicated the entire series of analyses described above on a set of 1000 ultrametric trees. To obtain the ultrametric trees, we used the initial set of 1000 trees and transformed the branch lengths using TreeEdit v.1.0a10 (Rambaut and Charleston, 2002) by implementing the non-parametric rate smoothing (Sanderson, 1997) option and weighting the rate differences at all nodes with the mean.

\section{Results}

\subsection{Phylogenetic analyses}

Table 1 provides data set characteristics and tree statistics for the analyses. Pairwise comparisons of the ML bootstrap analyses of the individual markers (Suppl. Figs. S2-S11) revealed 16 instances of well-supported ( $\geqslant 85 \mathrm{BP}$ ) topological incongruity. Nearly all topological conflict among these gene trees exists at localized and shallow levels of the phylogeny, primarily involving ten distantly related Euphorbia species that each have alternative placements among closely related species. An eleventh species, $E$. pachysantha, differs from the above cases because it is resolved with strong support as sister to different sectional-level clades within subgenus Euphorbia (Clade C) in rpl16 (Suppl. Fig. S6) and rps3 (Suppl. Fig. S9) analyses.

Given the broad congruence among these partitions, we analyzed them in combination as "total evidence." Parsimony, ML, and Bayesian analyses of the combined data set resolved topologies that were mutually congruent and generally strongly supported throughout (Fig. 3a and 3b). ML bootstrap support greatly increased in the combined analysis for many clades that were moderately or poorly supported in the analyses of individual markers.

The backbone topology of major lineages within tribe Euphorbieae uniformly has strong branch support values in the combined data set, with parsimony and ML BP values of 100 and $\mathrm{PP}$ of 1.0. Euphorbieae subtribes Anthosteminae (Anthostema and Dichostemma) and Neoguillaumininae (Calycopeplus and Neoguillauminia) are successively sister to Euphorbiinae (Euphorbia sensu lato; Fig. 3a). The four subgenera of Euphorbia are each monophyletic, with subgenus Esula (Clade B; Fig. 3a) sister to the other subgenera. In turn, subgenus Rhizanthium (Clade A; Fig. 3a) is sister to a clade consisting of subgenera Euphorbia (Clade C) and Chamaesyce (Clade D), shown in Fig. 3b. Results of the AU test indicate the constraint trees representing the two rival hypotheses $(1:[(A(B(C, D)))]$ and $2:[((A, B)(C, D))])$ of the backbone relationship within Euphorbia have likelihood scores that are significantly worse than that of the unconstrained tree ( 1 and 2 : $P<0.0001)$. 


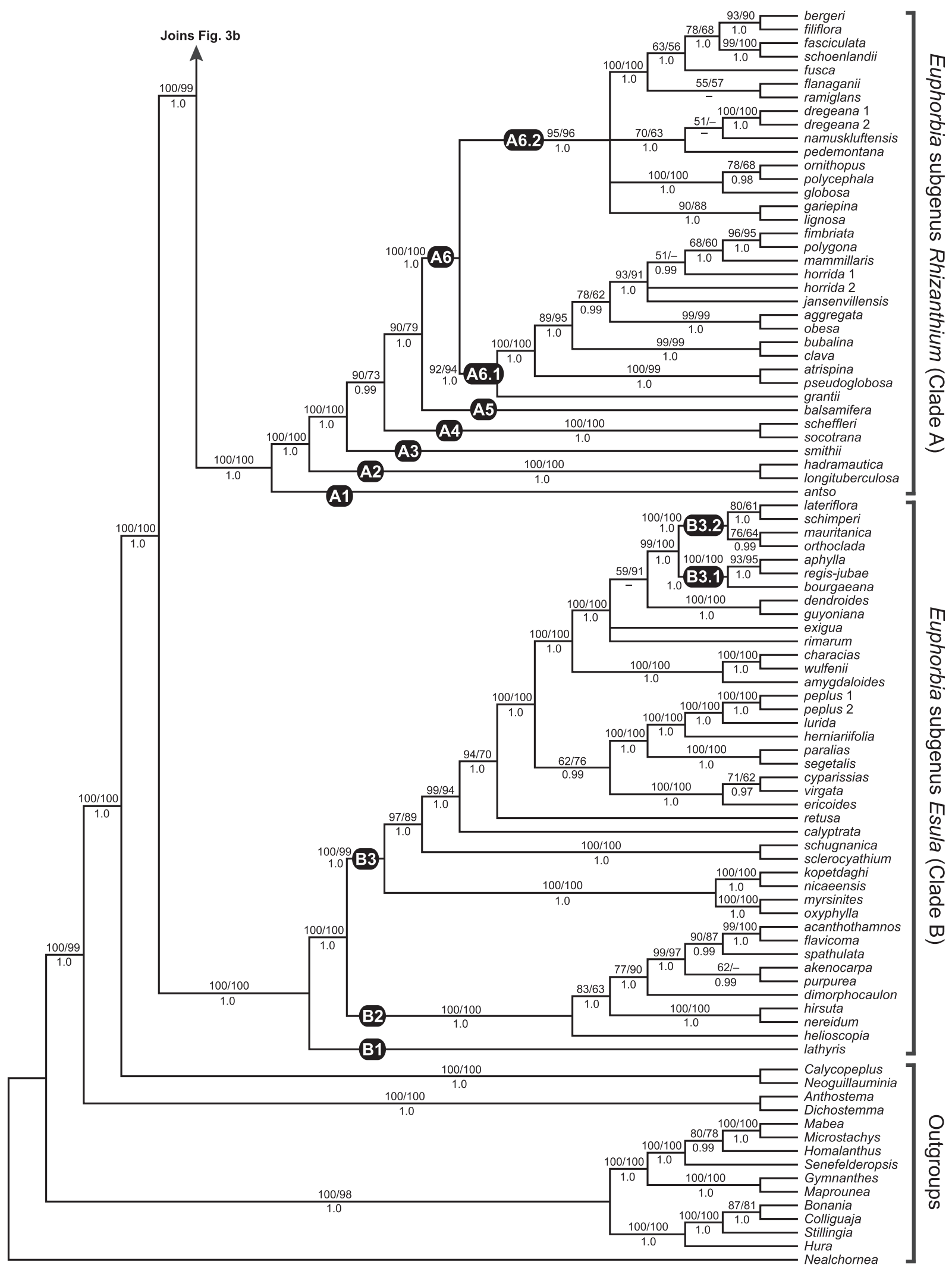

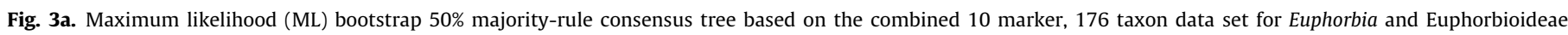

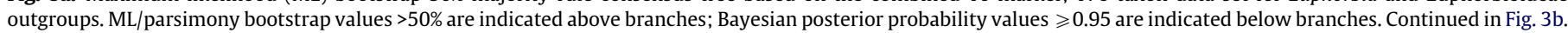

\subsection{Ancestral state reconstructions and comparative analyses}

Cyathial gland merosity (Character 1 ) is equivocal at the root node of Euphorbia (Fig. 4a), which is expected given that all the outgroups were scored as missing or inapplicable for this character, but it is reconstructed as five glands at all other backbone nodes, as well as the root nodes for Clades A, C, and D (Figs. 4b and 4c). Four glands is reconstructed as the ancestral state for the root node of 


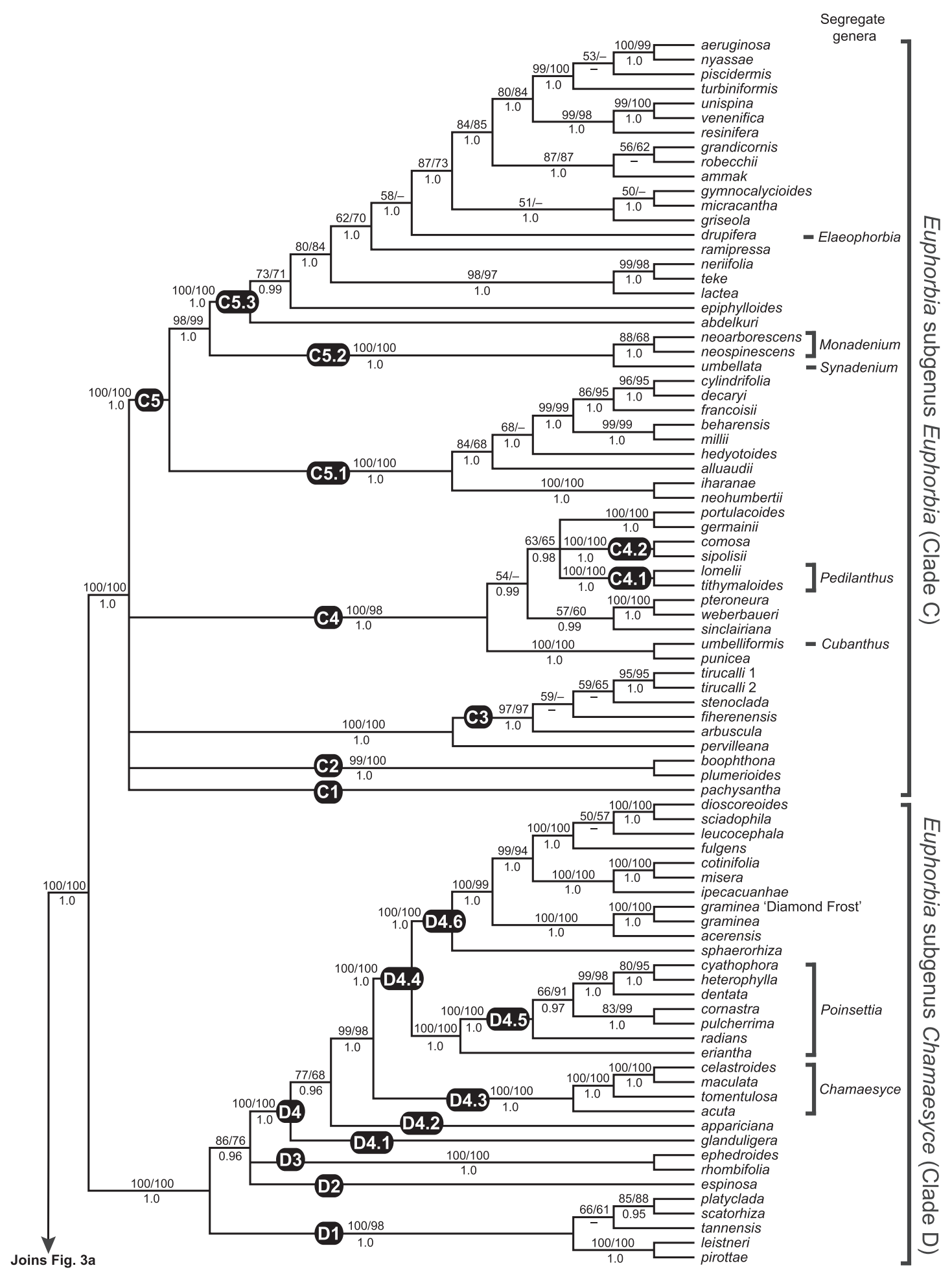

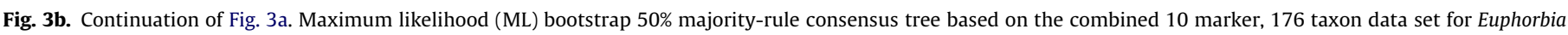
and Euphorbioideae outgroups.

Clade B (Fig. 4a). Gland appendages (Character 2) are reconstructed as absent at the root node of Euphorbia in most of the 1000 trees we examined (absent: 721, equivocal: 279), and as absent at the backbone nodes in every tree (Figs. 4a-4c). Among the subgenera, unappendaged glands are reconstructed as the ancestral state at the root nodes of Clades A, C, and D (Figs. 4b and 4c). Gland appendages are independently derived within each of these three subgeneric clades. Clade B has a complex distribution of gland appendages, and its root node has an equivocal optimization. Owing to equivocal reconstructions of many deep nodes within Clade B, just two unequivocal transitions occur within the group involving the loss of appendages along the stem lineage of subclade B3.2 and in E. guyoniana. Caruncles (Character 3 ) have a complex distribution within Euphorbioideae. The reconstruction at the root node of Euphorbia is equivocal (Fig. 4a). In the crown clade of Euphorbia sister to Clade B, caruncles are reconstructed as absent at all deep nodes, including 


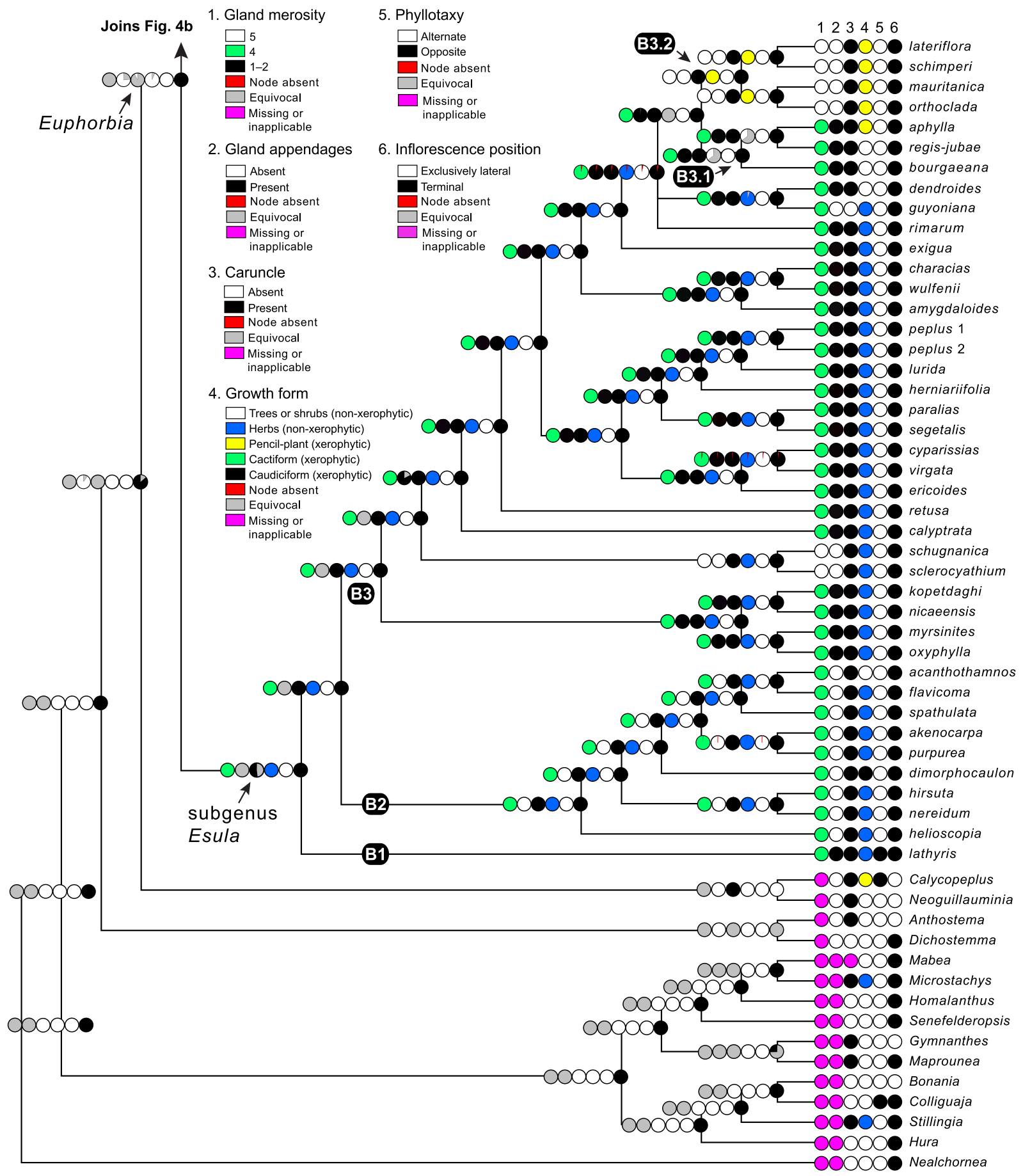

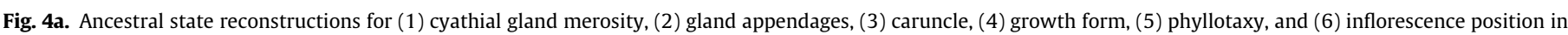

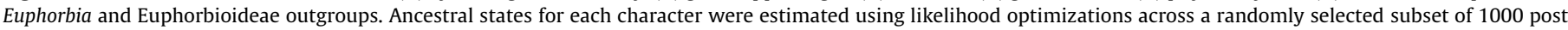

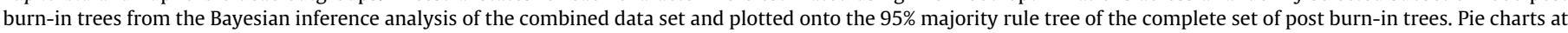

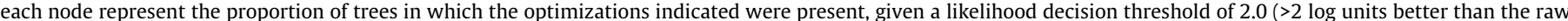
likelihood value(s) of the other states). Shown here are optimizations for Euphorbioideae outgroups and Euphorbia subgenus Esula; continued in Figs. 4b and 4c.

the root, the root of Clade $C+D$, and at the root nodes of Clades $\mathrm{A}, \mathrm{C}$, and D. The asymmetrical model of character evolution we used to optimize this trait favors a scenario of multiple, independent gains of caruncles within both Clades $\mathrm{C}$ and $\mathrm{D}$; caruncles are absent from Clade A (Figs. 4b and 4c). In contrast, caruncles are present in all but one species we scored from Clade $B$, but they are reconstructed as unequivocally present at the root node of this clade in just over half of trees that we examined (Fig. 4a; present: 521, equivocal: 479).
Trees and shrubs are reconstructed as the ancestral growth form (Character 4 ) at all deep nodes within the phylogeny, including all backbone nodes of Euphorbia (root node of Euphorbia, woody: 937, equivocal: 63). Among the subgeneric clades, a transition to the herbaceous habit is likely to be a synapomorphy for Clade $\mathrm{B}$ (Fig. 4a). A non-succulent, woody growth form is the ancestral state at the root nodes of Clades A and C (Figs. 4b and 4c). The root node of Clade $D$ is woody in just over half of the reconstructions, but equivocal in the rest (Fig. 4c; woody: 529, equivocal: 471). 


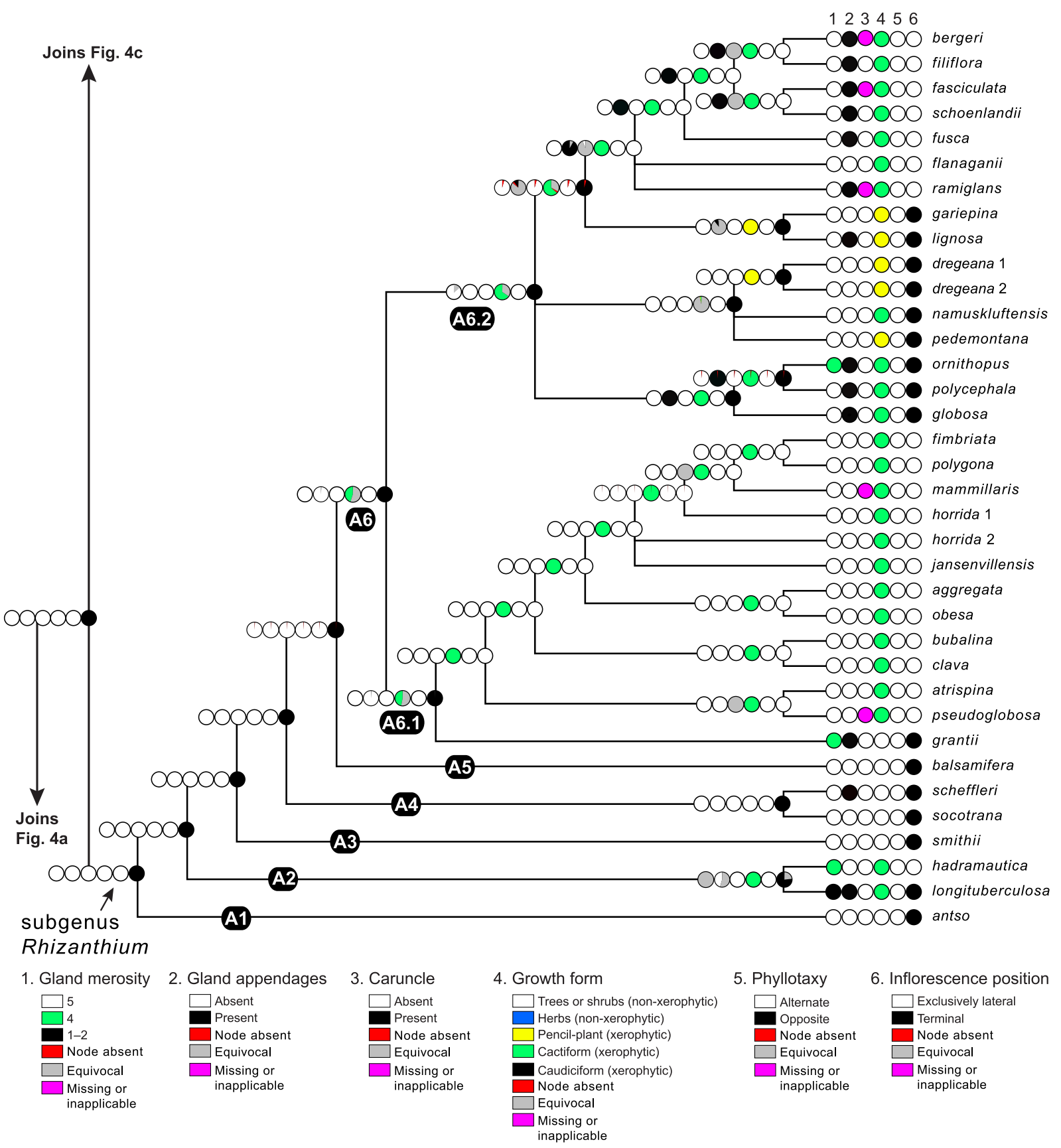

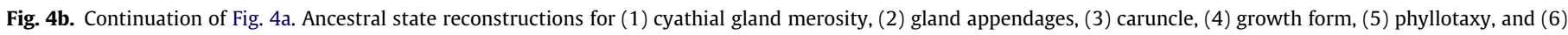
inflorescence position in Euphorbia and Euphorbioideae outgroups. Shown here are optimizations for Euphorbia subgenus Rhizanthium; continued in Fig. 4c.

Our reconstruction of phyllotaxy (Character 5) indicates that alternate leaves are the ancestral state at all deep nodes in the phylogeny, including the backbone nodes within Euphorbia. Taxa that transition to opposite or whorled phyllotaxy are concentrated in Clade D (Fig. 4c). Terminal inflorescences (Character 6) are the ancestral state at all deep nodes in the phylogeny, including all backbone nodes within Euphorbia. Transitions to exclusively lateral inflorescences independently occurred within Clades A, C, and D (Figs. 4b and 4c).

Results of the omnibus test analyses support a hypothesis of correlated evolution between growth form and inflorescence position (Tables 2 and 3 ). The Bayesian implementation of the omnibus test yields strong evidence in favor of the Dependent model, with a Bayes factor of 7.54. Likewise, the ML implementation of the omnibus test over the set of 1000 trees always rejected the Independent model in favor of the Dependent model (Table 3). Bayesian posterior probability values of each of the eight transition rate parameters ( $Z$-scores) indicated all but two of the categories, $q_{42}$ and $q_{34}$ (Fig. 5), had a high probability of being non-zero (Table 2). Similarly, the ML-based tests of the eight alternative models failed to reject the null hypothesis that the given transition rate category was significantly different from zero over all 1000 trees for just $q_{42}$ and $q_{34}$ (Table 3 ). Alternative model tests for transition rate categories $q_{21}$ and $q_{31}$ failed to reject the null hypothesis at the $P=0.05$ level across $0.2 \%$ and $96 \%$ of the 1000 trees, respectively. Alternative model tests of the remaining four rate categories rejected the null hypothesis across all trees (Table 3 ). In the contingency and ordering tests, Bayesian methods yielded evidence in 


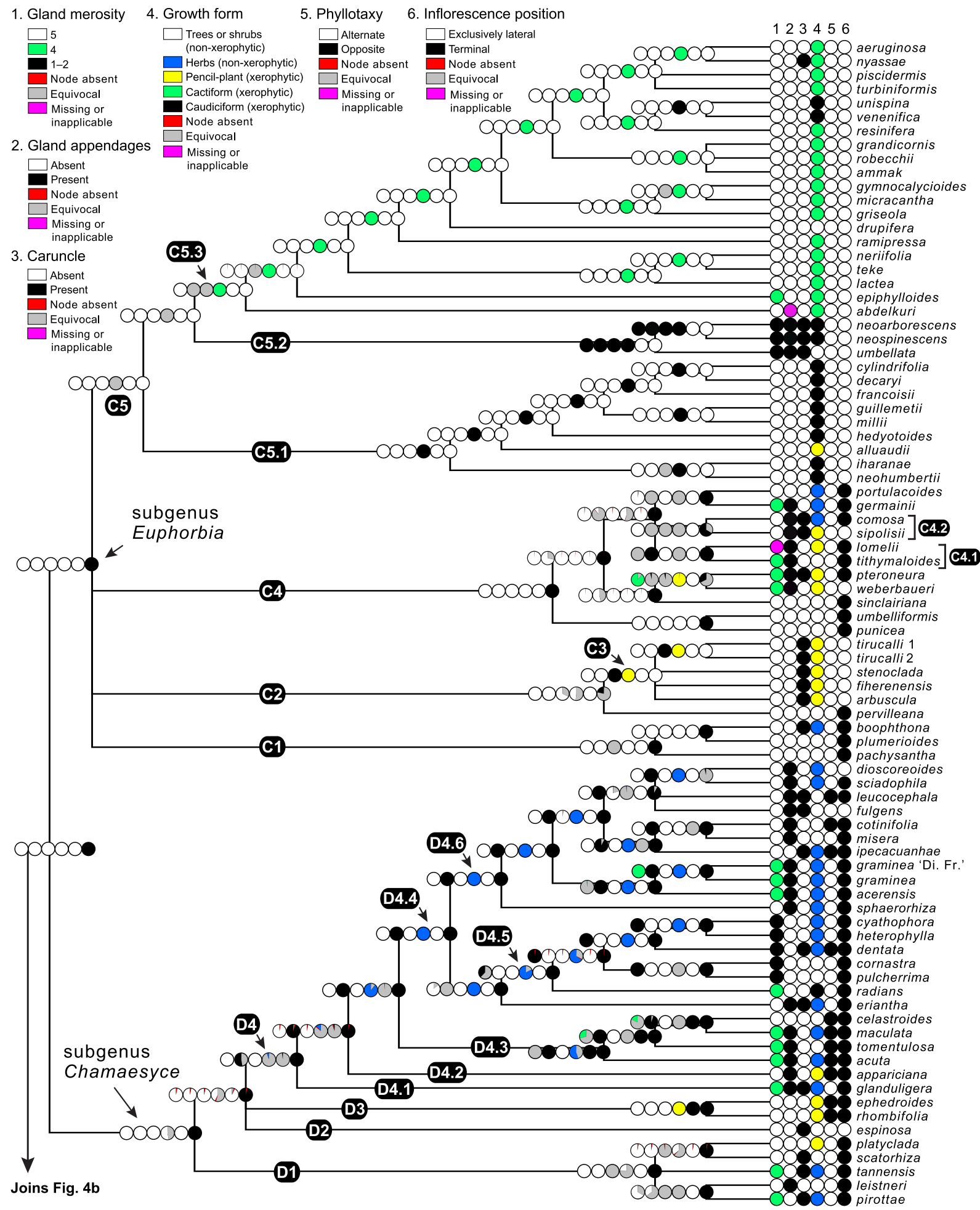

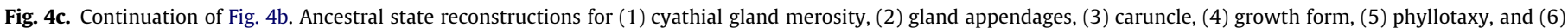
inflorescence position in Euphorbia and Euphorbioideae outgroups. Shown here are optimizations for Euphorbia subgenera Chamaesyce and Euphorbia.

favor of the null hypotheses of equal transition rates between $q_{13}$ and $q_{24}$, and $q_{12}$ and $q_{13}$ (Table 2). The ML implementation of these two tests yielded broadly analogous results, failing to reject the null hypothesis of $q_{13}=q_{24}$ at the $P=0.05$ level in $96.9 \%$ of the 1000 trees examined, and failing to reject the null hypothsis of $q_{12}=q_{13}$ across all trees (Table 3 ). The same series of tests conducted over the set of 1000 ultrametric trees gave results similar to those described above (Suppl. Tables S3 and S4).

\section{Discussion}

4.1. Euphorbia backbone phylogenetics and major systematic implications

Our results are fundamentally congruent with those of other studies examining the relationships among the different genera of the tribe Euphorbieae (Steinmann and Porter, 2002; Wurdack 
Table 2

Results of Bayesian correlation, contingency, and temporal ordering tests between inflorescence position and growth form using 1000 phylograms from the post burn-in period of the Bayesian phylogenetic analysis. Z-scores for each of the eight transition rate categories are given in the lower half of the table. A Z-score $<0.05$ indicates high probability of a rate category having a non-zero value. See Fig. 5 for further details on the transition rate categories $\left(q_{i j}\right)$.

\begin{tabular}{ll}
\hline Test & Bayes factor \\
\hline Omnibus (Independent vs. Dependent model) & 7.540 \\
Contingency & \\
$q_{13}=q_{24}$ vs. $q_{13} \neq q_{24}$ & -2.003 \\
Temporal order & \\
$q_{12}=q_{13}$ vs. $q_{12} \neq q_{13}$ & -2.872 \\
Rate category & Posterior probability of rate \\
& category with value of zero \\
\hline$q_{12}$ & $Z=0$ \\
$q_{13}$ & $Z=0.0210$ \\
$q_{21}$ & $Z=0.0239$ \\
$q_{31}$ & $Z=0.0195$ \\
$q_{24}$ & $Z=0.0001$ \\
$q_{42}$ & $Z=0.8056$ \\
$q_{34}$ & $Z=0.1795$ \\
$q_{43}$ & $Z=0.0002$ \\
\hline
\end{tabular}

Table 3

Results of maximum likelihood correlation, contingency, temporal ordering, and alternative model tests between inflorescence position and growth form using 1000 phylograms from the post burn-in period of the Bayesian phylogenetic analysis Significance of the $-2 \ln L$ values was assessed in the context of a $\chi^{2}$ distribution with four degrees of freedom for the Omnibus test and one degree of freedom for the remaining tests. See Fig. 5 for further details on the transition rate categories $\left(q_{i j}\right)$

\begin{tabular}{lll}
\hline Test & $\begin{array}{l}\text { Likelihood ratio test } \\
\text { statistic }(-2 \ln L)\end{array}$ & $\begin{array}{l}P \text {-value range } \\
\text { for }-2 \ln L\end{array}$ \\
\hline $\begin{array}{l}\text { Omnibus }\left(H_{0}: \text { Independent model; }\right. \\
\left.H_{1}: \text { Dependent model }\right)\end{array}$ & $16.952-22.887$ & $0.002-0.0001$ \\
Contingency & & \\
$H_{0}: q_{13}=q_{24}$ & $2.235-4.244$ & $0.135-0.035$ \\
Temporal order & & \\
$H_{0}: q_{12}=q_{13}$ & $0.992-2.584$ & Not significant \\
Alternative model & & \\
$H_{0}: q_{12}=0$ & $24.807-34.941$ & $<0.0001$ \\
$H_{0}: q_{13}=0$ & $6.361-9.481$ & $0.012-0.002$ \\
$H_{0}: q_{21}=0$ & $3.342-9.945$ & $0.068-0.0016$ \\
$H_{0}: q_{31}=0$ & $1.521-4.841$ & $0.217-0.028$ \\
$H_{0}: q_{24}=0$ & $6.536-26.132$ & $0.011-<0.0001$ \\
$H_{0}: q_{42}=0$ & 0 & Not significant \\
$H_{0}: q_{34}=0$ & $0.012-0.756$ & Not significant \\
$H_{0}: q_{43}=0$ & $13.209-19.329$ & $0.0002-<0.0001$ \\
\hline
\end{tabular}

et al., 2005; Park and Jansen, 2007). The subtribal lineages Anthosteminae (Anthostema and Dichostemma) and Neoguillaumininae (Calycopeplus and Neoguillauminia) are successively sister to subtribe Euphorbiinae, which under a sensu lato circumscription of Euphorbia only contains that genus (i.e., all segregates subsumed). All Euphorbia species in our analyses were resolved within one of four major subgeneric clades identified in all previous molecular phylogenetic studies of the genus, in which sampling was guided by the major classification schemes for Euphorbia (e.g., Boissier, 1862; Webster, 1967). Our results are also consistent with a range of contemporary studies from the collaborative PBI project, which collectively aim to establish the phylogenetic placement of all known species of Euphorbia. None of the studies underway in this project have so far revealed any new major lineages in the genus. Hence, the four-clade hypothesis of Euphorbia phylogeny is likely to prove stable.

Our strongly supported hypothesis of the relationships among the four subgeneric clades agrees with the conclusions of some
(Wurdack et al., 2005; Park and Jansen, 2007; Zimmermann et al., 2010, combined ITS and trnL-F), but not all previous studies (e.g., Steinmann and Porter, 2002) in resolving a topology in which subgenus Esula (Clade B), subgenus Rhizanthium (Clade A), subgenus Euphorbia (Clade C), and subgenus Chamaesyce (Clade D) are successively sister lineages. Branch support for this topology is much stronger than that obtained in any prior study, with ML and parsimony bootstrap support of 100 and PP of 1.0 for the whole of this topology. Furthermore, results of the topology tests indicate that this tree has a significantly better likelihood score than those with a topology constrained to conform to the two alternative hypotheses. In addition to establishing a robustly supported backbone topology, our results also provide significant new information on the relationships within each subgeneric clade.

Within subgenus Esula (Clade B), the most phylogenetically significant novel relationship discovered in our analyses is that Euphorbia lathyris (Fig. 3a, lineage B1) is strongly supported as sister to the remaining species of the subgenus. Steinmann and Porter (2002) and Zimmermann et al. (2010), using ITS data alone, inferred alternative placements for this species, and both placed it in a well-nested position within the subgenus. Although the ML bootstrap analysis of the ITS partition of our data did not resolve a well supported placement for E. lathyris within the subgenus, it is resolved as sister to the rest of the subgenus in all individual analyses of mitochondrial and plastid markers (Suppl. Figs. S2S10). Given its unique decussate phyllotaxy and late-dehiscing capsules with a thickened, spongy mesocarp, E. lathyris has long been viewed as a morphologically isolated species, and has been recognized as a monotypic section by several authors (Boissier, 1862; Prokhanov, 1949; Benedí et al., 1997). However, there is otherwise little structural evidence to suggest the phylogenetic position E. lathyris, and it resembles most other species in this clade in having exstipulate leaves, pleiochasial inflorescence architecture, cyathia with four glands, and carunculate seeds.

The topology of subgenus Esula exclusive of E. lathyris is generally strongly supported throughout, and is largely congruent with the results of other phylogenetic studies with a broad sampling of this lineage (Steinmann and Porter, 2002; Zimmermann et al., 2010; Frajman and Schönswetter, 2011). Two major clades are recovered that can be generally diagnosed by contrasted capsule surface sculpturing, with members of clade B2 typically with tuberculate capsules and members of clade B3 having capsules with smooth to granulate surfaces (Fig. 3a; Frajman and Schönswetter, 2011). Our results also suggest that clade B2 is further characterized by unappendaged cyathial glands, each with an evenly rounded distal margin. Species in clade B3 predominantly have two horn-shaped appendages associated with each of their cyathial glands (Hoppe, 1985; Frajman and Schönswetter, 2011), although gland shape has a complex distribution in this group (Fig. 4a). Unlobed cyathial glands characterize several lineages within this clade, with prominent examples being the African pencil-plant clade (subclade B3.2, Fig. 3a), and the small Asian subclade of E. schugnanica and E. sclerocyathium (Fig. 4a); both of these groups also differ from the rest of the clade in having a secondarily derived condition of five gland appendages. Detailed investigations of comparative seed morphology (Vindt, 1953; Molero et al., 1996) and leaf anatomy (Vindt, 1960) show promise for reconciling the substantial morphological variation of subgenus Esula in a phylogenetic context.

For subgenus Rhizanthium (Clade A), our analyses resolve a strongly supported backbone topology within this clade, which is best conceptualized as consisting of six successively sister lineages. As shown in Fig. 3a, these are: (A1) E. antso, a small tree from Madagascar; (A2) a small clade of semi-succulent, tuberculatestemmed herbs formerly accommodated in subgenus Eremophyton 


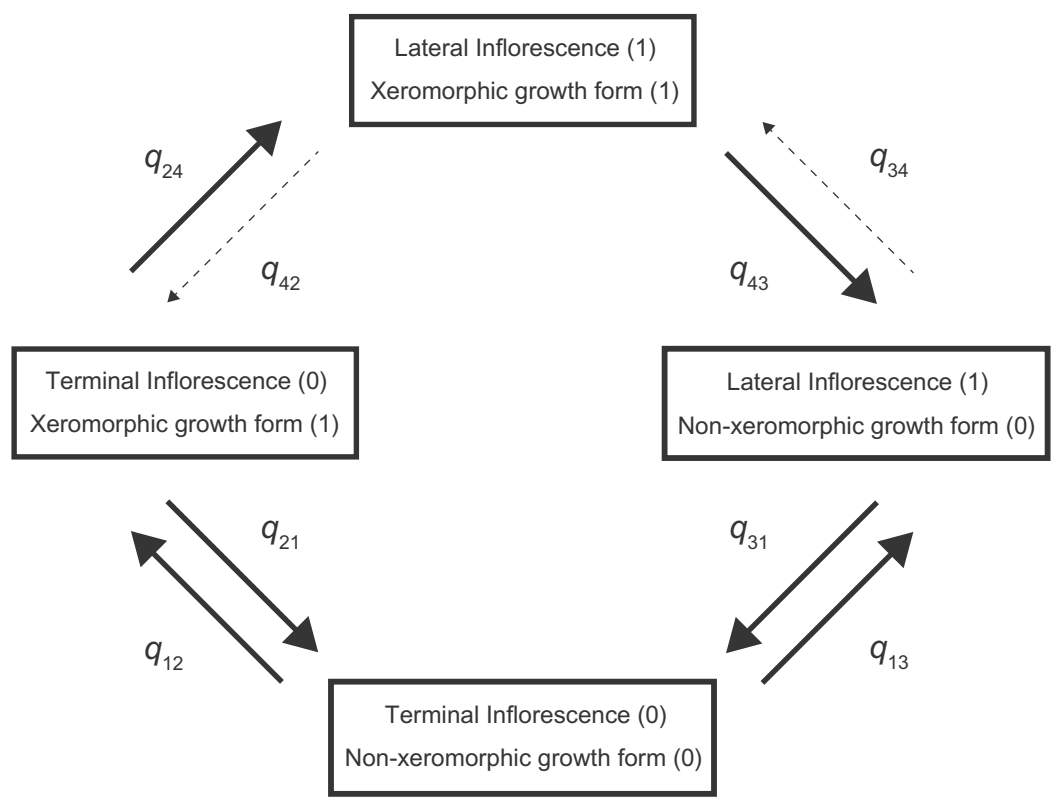

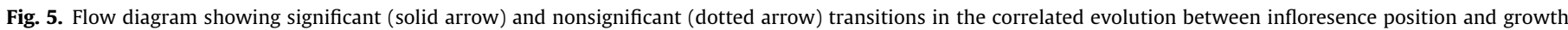

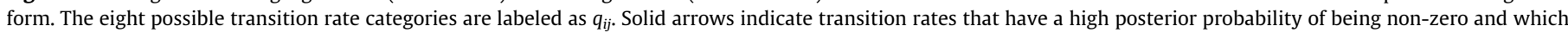

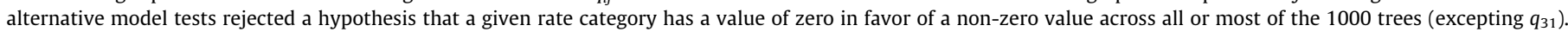

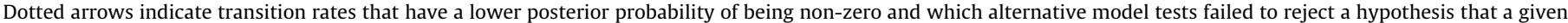
rate category has a value of zero across all trees examined.

in the concept of Carter (1985) and Holmes (1993), exemplified here by E. longituberculosa and E. hadramautica; (A3) a lineage forming part of the arborescent, predominantly tropical African section Lyciopsis, represented here by E. smithii (Carter, 1988a); (A4) a clade including representatives of the arborescent, tropical African section Somalica (Carter, 1985, 1988a,b); (A5) E. balsamifera, representative of a small group of shrubby species centered in northern Africa and the Arabian Peninsula; and finally (A6) a major radiation of largely southern African succulents, geophytes, and caudiciform or strongly pachycaulous shrublets. This last clade is by far the most species-rich group of the subgenus, and has been subdivided into numerous groups of varying circumscription and rank by different authors (Steinmann and Porter, 2002; Ritz et al., 2003; Bruyns et al., 2006). This clade also exemplifies the well-known phenomenon of apparent decoupling of rates of morphological and molecular evolution. The limited amount of sequence divergence within this clade, evident in the comparatively very short branch lengths throughout the group (Suppl. Fig. S1), belies the enormous diversity of xeromorphic growth forms present among its constituent species. Although subgenus Rhizanthium is overall not readily characterizable from a structural perspective, it is distinctive in that the seeds of its constituent species apparently always lack a caruncle.

Within subgenus Euphorbia (Clade C), our combined analyses inferred five distinct lineages of markedly unequal size, each with significant support, although the relationships among them remain unclear. Euphorbia pachysantha, representative of a small group of arborescent Madagascan species that are distinctive in having cyathia with male flowers borne within a tightly enveloping series of bracteoles (Rauh, 1996; Aubriot, 2008), is the most recalcitrant species to place in our analyses (lineage C1; Fig. 3b). In the combined ML and parsimony analyses, it is resolved as sister to all other taxa of the subgenus, but without significant support (BP $<50$ for both methods). Support for its placement in the ML bootstrap analyses of individual marker partitions, when evident, is conflicting, with two different placements resolved. Analyses of mitochondrial rps3 support a sister relationship with a clade of
E. plumerioides and E. boophthona (BP 94)-a relationship which is also resolved in the Bayesian analysis of the combined data set (PP 0.99). In contrast, data from plastid $r p l 16$ and $n d h F$ indicate a placement sister to a predominantly Madagascan clade including section Tirucalli (clade C3) and E. pervilleana with BP support of 93 and 51, respectively. The latter relationship makes sense biogeographically and morphologically because members of the E. pachysantha group share character states with, at least, the E. pervilleana group that are otherwise rare in Euphorbia, such as bicarpellate gynoecia and indehiscent fruits (Haevermans and Labat, 2004; Aubriot, 2008).

Other than that mentioned above, the relationship of the Australopacific E. plumerioides group (clade C2; Fig. 3b) to other lineages within the subgenus is obscure. The putative members of this small clade are morphologically quite disparate. Euphorbia plumerioides and closely related species are all shrubs to small trees of lowland, semideciduous to humid montane forests (Forster, 1994). Zimmermann et al. (2010) demonstrated that the unusual Australian pencil-plant shrub E. sarcostemmoides is to be included in this lineage. Despite its dissimilar appearance, it resembles most other members in having cyathia with five glands and ecarunculate seeds. Another member of clade C2, E. boophthona, contrasts with all putative members of this clade in having cyathia with four glands and seeds with caruncles. These character states, along with the herbaceous habit of the species, are suggestive of a placement in subgenus Chamaesyce near E. tannensis (Hassall, 1977), as Zimmermann et al. (2010) resolved for their accession of this species. Additional specimens of E. boophthona should be sought and examined to resolve this discordance.

The monophyly of the three most species-rich lineages of subgenus Euphorbia is each strongly supported. These clades correspond to: (C3) a clade of section Tirucalli (sensu Bruyns et al., 2006, in part; but with the E. pervilleana species group separate from the main clade of pencil plants); (C4) a clade containing all of the New World taxa of the subgenus; and (C5) a clade containing the largely African and Madagascan xerophyte subclades of sections Euphorbia (subclade C5.3), Goniostema (subclade C5.1), and 
Monadenium (subclade C5.2; Fig. 2p). A robust hypothesis of the relationships among the morphologically diverse lineages that comprise the New World clade has been difficult to establish on account of the very short branches deep within the group, possibly suggesting a rapid radiation. The relationships of the distinctive slipper spurge group, section Crepidaria (subclade C4.1; formerly recognized as Pedilanthus; Steinmann, 2003), to other lineages in subgenus Euphorbia has been especially difficult to establish due to insufficient sampling and the unusually long stem branch of the clade (Cacho et al., 2010). However, we robustly resolve it within the New World clade (clade C4), included within a subclade that also contains species of sections Nummulariopsis (E. germainii and E. portulacoides), Stachydium (E. comosa) and Euphorbiastrum (E. sipolisii). The parsimony bootstrap analysis moderately supports (BP 75) a more finely resolved placement of section Crepidaria as sister to section Stachydium (subclade C4.2). The potential close relationship between section Crepidaria and section Stachydium is intriguing from a structural perspective because both of these groups are unlike all other members of the subgenus in having a pronounced dorsiventrality to their shoot systems. This is evident in the strict distichy of the bracts of the unusual monochasial inflorescences of section Stachydium, and in the distichous arrangement of foliage leaves on those members of section Crepidaria.

Within subgenus Chamaesyce (Clade D), our combined analyses resolve four, strongly supported, major lineages (Fig. 3b). The topology we recover for this clade is largely congruent with that recovered by Zimmermann et al. (2010), which indicates an early, predominantly African radiation within the subgenus and a subsequent single origin of the New World taxa. The four major lineages we recognize within the group are: D1) a clade corresponding to the expanded concept of section Frondosae of Bruyns et al. (2006); D2) E. espinosa, representing section Espinosae, which contains two species of deciduous shrubs indigenous to central and southern Africa; D3) a clade comprised of two representatives of the mostly southern African section Articulofruticosae; and D4) a clade containing all sampled lineages of the subgenus in which each gland of the cyathium appears subtended by a petaloid appendage-a group we refer to as the petaloid appendage clade.

The section Frondosae clade (clade D1) is strongly supported as sister to all other members of subgenus Chamaesyce. Our data strongly support the inclusion of E. tannensis, representative of a small group of morphologically similar Australopacific species, within this section. The relationships among the other three main lineages of subgenus Chamaesyce are poorly resolved. However, in both the ML topology and the parsimony strict consensus tree, $E$. espinosa (lineage D2) is sister to a clade inclusive of section Articulofruticosae (clade D3) and the petaloid appendage clade (clade D4).

Within the petaloid appendage clade there are four principal, successively sister lineages (D4.1-D4.4; Fig. 3b). Euphorbia glanduligera (lineage D4.1) represents a clade of five annual species indigenous to southern Africa (Steinmann and Porter, 2002; Zimmermann et al., 2010). Its sister clade contains lineages (D4.2-D4.4) that are primarily or exclusively distributed in the New World. Euphorbia appariciana (lineage D4.2) represents section Crossadenia, a primarily Brazilian group of about nine species of herbs or semisucculent to succulent subshrubs. The clade of section Anisophyllum (subclade D4.3; formerly recognized as the genus Chamaesyce) contains about 350 species of herbs and shrubs. Yang and Berry (2011) indicated that the clade originated in North America and attained its nearly worldwide distribution through multiple long-distance dispersal events. Subclade D4.4 has an entirely New World distribution and contains most of the species formerly included within subgenus Agaloma (Wheeler, 1943; Webster, 1967). Subclade D4.6, corresponding to section Alectoroctonum, is a structurally variable group centered in southwestern North America that contains about 120 of the nearly 160 species of subclade D4.4. Section Poinsettia (subclade D4.5) is also included within subclade D4.4.

Given the large disparity in species richness between lineage D4.1 and its sister clade (D4.2-D4.4), which contains about 500 species, we suggest that a new physical opportunity for this lineage, apparently effected by a single dispersal event to the New World, might have been a factor in promoting its diversification.

\subsection{Morphological character evolution}

Character state distributions of many traits in Euphorbia, including those we analyzed, are homoplasious across the genus as a whole. In the absence of molecular phylogenetic information, the complexity of character state distributions, while always thought to be substantial, was actually underestimated in many instances. This, on the one hand, led to frequent misinterpretations of relationships within the genus, but on the other hand, sometimes emphasized the biological distinctiveness of the groups so characterized. A prime example of such a group is the former concept of section Tirucalli (Boissier, 1862) or subgenus Tirucalli (Carter, 1985), in which most of the Old World pencil-plant xerophytes were placed. According to our molecular analyses and character state reconstructions, members of this group now emerge as distinct lineages within each of the four subgenera of Euphorbia (Fig. 2e-h).

Although most previous ideas on the early evolution of Euphorbia focused on the origin of the cyathium (see Prenner and Rudall, 2007 for a review), three studies, Dressler (1957), Webster et al. (1982), and Steinmann and Porter (2002) provided hypotheses of the ancestral Euphorbia. Each proposed different taxa as exemplifying the ancestral condition of Euphorbia. Their hypotheses, however, are relatively congruent with one another, and also with the results of our character analyses, in specifying that the ancestor of Euphorbia was a non-succulent, woody plant with alternate (helical) phyllotaxy that bore cyathia in terminal inflorescences. Gland merosity is equivocal at the root node of Euphorbia in our reconstructions. Regardless of the apparent gland number, the cyathial involucres of all Euphorbia species that have been investigated developmentally or anatomically have a 5-merous groundplan (Dressler, 1957; Venkata Rao, 1971; Hoppe, 1985; Hoppe and Uhlarz, 1982), which is perhaps indicative of the plesiomorphic state for gland merosity in the genus. The presence of a caruncle on the mature seed also has an equivocal reconstruction at the root node of Euphorbia, but this is not surprising given the substantial lability in the presence or absence of this trait within Euphorbia and Euphorbiaceae as a whole (Wurdack et al., 2005; Tokuoka, 2007). Overall, our analyses establish that most of structural features we investigated evolved within the genus and the diversity of xeromorphic forms for which Euphorbia is best known, are novelties with independent origins within each of the subgeneric clades.

\subsubsection{Evolution of reproductive traits}

The cyathium is a distinctive type of pseduanthium that is the only known structural synapomorphy unique to Euphorbia. As shown in Fig. 1a, it consists of a cup-like involucre of fused bracts that includes a central, terminal, perianthless female flower surrounded by a whorl of usually five lateral clusters of male flowers, each of which is reduced to a single stamen (Prenner and Rudall, 2007). The rim of the involucral cup usually bears four or five glands that often secrete nectar. A suite of synapomorphic character states characterize the cyathium of Euphorbia relative to the less modified pseudanthia present in Anthosteminae and Neoguillaumininae, including the reduction of bracteoles and bracts associated with male flowers, the loss of a perianth in the male flowers, and changes in the organization of the male flower clusters (Prenner and Rudall, 2007; Prenner et al., 2008). Because of these 
structural changes, which are possibly mediated by an expansion of the expression of the floral identity conferring FLORICAULA/LEA$F Y$ (LFY) protein to include the entire cyathium primordium (Prenner et al., 2011), the mature cyathium attains a remarkable similarity with basic eudicot floral structure in both body plan organization and Gestalt.

The basic cyathial structure within Euphorbia is relatively uniform. However, pronounced diversity exists in the shape, coloration, ornamentation, number, and position of the cyathial glands, and major variants have been emphasized in delineating most of the previously recognized satellite genera (Fig. 3b). Of these traits, variation in cyathial gland merosity and the presence or absence of appendages associated with each cyathial gland are among the most apparent aspects of cyathial diversity that can be quantified throughout the genus.

Cyathial gland merosity is a relatively labile trait in Euphorbia, with numerous transitions between five and four glands. Subgenus Esula is the most conserved in this regard among the four subgeneric clades, and differs from the other three in having cyathia with four glands as both the ancestral state and the most common condition within the clade. There have been just two changes in cyathial gland merosity within subgenus Esula, in both cases from a 4- to a 5-merous condition. This occurred independently in the pencilplant subclade B3.2 (Fig. 2a) and in the small subclade of E. schugnanica and E. sclerocyathium. In the other three subgenera, 5-merous cyathia are plesiomorphic, and transitions to 4-merous cyathia are always derived. In many of these instances, notably in the subclade of section Anisophyllum (subclade D4.3, Fig. 2b) and the E. graminea species group, the loss of a gland induces a subtle to moderate bilateral symmetry in the cyathia of these groups. Based on pollination biology reports of members of section Anisophyllum, which have 4-merous cyathia, it is unlikely that this symmetry shift effects a corresponding shift in pollination mechanism (Ehrenfeld, 1979). Rather, it seems that the principal functional benefit might be that the gap left by the absent gland accommodates the elongated, recurved pedicel of the post-anthetic female flower, thereby preventing it from obstructing access to the mouth of the cyathium during the later male phase of reproduction.

In subgenera Chamaesyce and Euphorbia, modifications in gland architecture can more extensively involve the entire whorl of glands as a unit, in contrast with the other two subgenera, in which variation is primarily expressed at the level of the individual gland. The most extreme variants occur in the clades of subgenus Euphorbia consisting of the formerly recognized satellite genera Cubanthus, Monadenium, Pedilanthus, and Synadenium (Fig. 3b). Except for cyathia of species in section Crepidaria (subclade C4.1; Figs. 1d and $3 \mathrm{~b}$ ), these unusual cyathia usually bear a single gland, and this gland has a different shape in each of the major clades. Hoppe (1985) revealed that the single-glanded cyathia of section Monadenium (subclade C5.2; Figs. 3b and 4c) develop from the fusion of the entire whorl of glands and associated appendages. Cyathia of E. umbellata (=Synadenium) bear a ring-shaped gland that is the product of the fusion of tissues from five gland positions, whereas the horseshoe-shaped glands of species formerly contained in the genus Monadenium (Fig. 3b) develop from the four adaxial-most (uppermost) glands of the cyathium (Hoppe, 1985). The latter type of nectary gland confers bilateral symmetry to the cyathia of these species, but their pollination mechanism is unknown. Cyathial gland fusion, although expressed to an extreme in section Monadenium, is also expressed in its sister clade, section Euphorbia (subclade C5.3). Here, the cyathial glands are usually basally fused, with each of the (typically) five glands apically discrete (Fig. 20).

Single-glanded cyathia can possibly also develop by the suppression of all but one gland. Our analysis demonstrates lability in cyathial gland number in the clade of the characteristically single-glanded section Poinsettia (subclade D4.5; Figs. 1f, 3b, 4c). In this group, the early-diverging $E$. radians bears cyathia with four of the cup-shaped, unappendaged glands that are diagnostic for the group, suggesting that a reduction in the number of glands expressed, and not the fusion of several glands, effects the singleglanded condition of the cyathia in other members of the section.

Gland appendages arose independently within each of the subgeneric clades. All cyathial gland appendages in Euphorbia, however, share positional and early developmental features (Hoppe, 1985), suggesting that basic aspects of their pattern formation may have a common genetic basis (Scotland, 2010). Despite the ambiguous origin and early evolution of gland appendages in subgenus Esula (Fig. 4a), gland appendages, when present, are of a distinctive and rather uniform type for the group in being paired on each gland so that the gland appears two-horned (Fig. 1e). Within subgenus Rhizanthium, there are at least five origins (Fig. 4b) of gland appendages, which typically are digitate and occur in a series of three or more at the distal margin of each gland. Reports of carrion fly pollination in Euphorbia are restricted to species of this subgenus that have gland appendages of this type (Vogel, 1954).

Gland appendages have independent origins in section Monadenium (subclade C5.2) and the New World Clade (clade C4) within subgenus Euphorbia (Figs. 3b and 4c). Hoppe (1985) indicates that the large, solitary gland present in each cyathium of section Monadenium is predominantly produced from tissue homologous with the appendages, and not the gland bodies. The largest range of gland appendage form among any of the lineages we recognize within the subgenera is present in the New World clade (clade C4; Fig. 3b). Gland appendages of the slipper spurges, section Crepidaria (subclade C4.1; Figs. 1d, 3b, and 4c), are notable in that they have a novel protective function in addition to their role as a visual attractant. Slipper spurge cyathia typically have four petaloid appendages associated with the cyathial glands. These are restricted to the nectar spur, which represents a strongly modified zone of the cyathial involucre and is a trait unique to this clade (Dressler, 1957; Cacho et al., 2010). Because cyathial involucres are distally open structures, the appendages function as a unit to enclose the portion of the involucre forming the nectar spur. Nectar is released at the distal juncture of the gland appendage "cap" and the cyathial involucre (Fig. 1d).

Gland appendages have a single origin in the petaloid appendage clade of subgenus Chamaesyce in a majority of the trees we examined (clade D4; Figs. 3b and 4c), but our analyses do not preclude the possibility of independent origins of appendages in $E$. glanduligera and its sister clade. The appendages resemble petal blades-hence dubbed petaloid appendages-and are usually white, but vary substantially in size between species. Based on species belonging to section Anisophyllum, Ehrenfeld $(1976,1979)$ suggested that cyathium size, which is largely governed by appendage size, is positively correlated with pollination by larger-bodied insects-particularly bees-in this group. Interestingly, gland appendages have three independent losses within the petaloid appendage clade. The most significant of these characterizes, and is potentially synapomorphic for, section Poinsettia (subclade D4.5; Figs. 1f, 3b and 4c), and may be related to a transfer of display function from petaloid appendages to conspicuously pigmented subcyathial leaves.

The caruncle, when present in Euphorbia, can function as an elaiosome to attract ants that can further disperse the seeds after their initial, ballistic dispersal (Sernander, 1906; Berg, 1975; van der Pijl, 1982; Webster, 1994; Narbona et al., 2005; Lengyel et al., 2010). Elaiosomes have been postulated to have over 100 independent origins among the angiosperms, and they have been implicated as a key innovation, in association with ant dispersal, which promoted increased net diversification rates in many angiosperm groups (Forest et al., 2007; Lengyel et al., 2009, 2010). 
Although caruncles are sometimes generalized to be a constitutional feature of Euphorbia seeds, our character reconstructions demonstrate that, of the subgeneric clades, this is true of only subgenus Esula (Fig. 4a). Perhaps not coincidently, most studies that demonstrate seed dispersal by ants in Euphorbia focus on species of subgenus Esula (Sernander, 1906; Pemberton, 1988; Espadaler and Gómez, 1997; Narbona et al., 2005). However, caruncles were likely absent from the early radiation of the major lineage of Euphorbia that is sister to subgenus Esula. Within this clade of three subgenera, caruncles did not evolve within subgenus Rhizanthium. In contrast, caruncles originated independently at least 12 times within the clade of subgenera Chamaesyce and Euphorbia. The results of the asymmetry likelihood ratio tests for this character amplify those of the ancestral state reconstructions because a oneparameter model of evolution was nearly always rejected in favor of a two-parameter model with a significantly greater transition rate for caruncle gains. Hence, caruncle evolution in Euphorbia is dynamic and parallels that of angiosperms as a whole in having a pattern of multiple, independent origins.

Several Euphorbia taxa in which caruncles are absent or apparently lost are of interest because they have alternative mechanisms that enhance dispersal and germination. The only unambiguous instance of caruncle loss in Euphorbia in our data set occurs in E. guyoniana, a member of subgenus Esula that is native to the western Sahara Desert. It is unusual in having seeds covered by an irregular series of radially extended, spongy ridges that may facilitate water absorption after infrequent rainfall. An alternative seed dispersal mechanism evolved in section Anisophyllum (subclade D4.3; Figs. $3 \mathrm{~b}$ and $4 \mathrm{c}$ ). The ecarunculate seeds of most species of this clade have distinctive testa cells that develop polysaccharide-enriched, helical wall thickenings (Jordan et al., 1985; Jordan and Hayden, 1992). These become mucilaginous and sticky when hydrated and might function to adhere the seeds to potential dispersers.

\subsubsection{Evolution of growth forms and plant architecture}

Few, if any, angiosperm crown clades of comparable age to Euphorbia ( 42.5 million years before present; van Ee et al., 2008) exhibit such an extremely diverse and disparate range of growth forms. Growth form diversity is yet more remarkable from an evolutionary perspective, as our analyses reveal that the complexity is greater than previously thought. From a woody, non-succulent ancestor, there have been at least five independent origins of the herbaceous habit, at least seven transitions from herbs to secondary woodiness, and 14 origins of strongly xeromorphic growth forms. Inflorescence position and phyllotaxy are important components of branching architecture in Euphorbia; hence, transitions in these two traits are important correlates of growth form evolution in the genus. Inflorescence position is perhaps the more critical of these two traits because, in Euphorbia, it reflects the fundamental contrast between monopodial and sympodial architecture. This, in turn, is significant to the evolution of the strongly xeromorphic growth forms.

Euphorbia is well-known for its contingent of about 850 species that exhibit strongly xeromorphic growth forms, all of which have varying manifestations of stem or hypocotyl succulence. The most renowned of these are the many African species that are strongly convergent with the New World Cactaceae, but there also exists a diversity of photosynthetic stem succulents with slender and typically much-branched axes-the pencil plants-as well as an array of caudiciform shrubs. The multiple, independent origins of strongly xeromorphic growth forms in Euphorbia, which our analyses demonstrate evolved from woody, non-succulent ancestors in most instances, has as its likely basis the convergence of a suite of stem anatomical character states. Based on what is known of the stem anatomy of xeromorphic Euphorbia species (Trumpke, 1914; Steinmann, 2001; Mauseth, 2004), these likely include the abundant development of water-storage parenchyma, and, in photosynthetic stem succulents, delayed periderm production and a gain or increase in stem-borne stomata, as in cacti (Steinmann, 2001; Edwards et al., 2005). Xeromorphy is also associated with seven of the 10 transitions to lateral inflorescences in the clade of tribe Euphorbieae (Fig. 3) and, further, approximately 75\% of xeromorphic Euphorbia species have lateral inflorescences, which provided an initial suggestion that the evolution of inflorescence position and growth form may be correlated.

Indeed, a statistically significant correlation does exist between the evolution of growth form type and inflorescence position in Euphorbia (Tables 2 and 3; Suppl. Tables S3 and S4). The results of the alternative model tests and Bayesian Z-scores indicate a defined evolutionary pathway in the transitions between the four states of these two characters (Fig. 5). From a non-xeromorphic ancestor with terminal inflorescences, it is overwhelmingly more likely that terminal inflorescences attend transitions to xeromorphy; and, correspondingly, that xerophytes with lateral inflorescences evolve from a xeromorphic ancestor with terminal inflorescences. Interestingly, xerophytes with lateral inflorescences apparently do not transition back to terminal inflorescences, suggesting lateral inflorescences may confer a functional benefit relative to terminal inflorescences in Euphorbia xerophytes. We address this idea below. Transitions from xeromorphic growth forms to non-xeromorphic growth forms do occur in Euphorbia, with most known instances consisting of individual species confined to clade $\mathrm{C5}$, which contains taxa with lateral inflorescences. Our hypothesis tests also indicate that xerophytes with terminal inflorescences may revert to a non-xeromorphic growth from. However, ancestral state reconstructions of the two-state coding of growth form do not confirm any unambiguous cases in which such a transition actually occurs (Suppl. Fig. S12). Beyond what we just described, our results indicate no other significant contingencies to the evolution of xeromorphic growth forms and lateral inflorescences, and no significant ordering in the evolution of these two character states.

The possible evolutionary significance of lateral inflorescences to Euphorbia xerophytes is perhaps broader than the results of these tests can indicate. The strongly xeromorphic species of Euphorbia inhabit regions with at least seasonally arid climates, which is reflected in the seasonality of growth in these plants. In species with shoots terminating in inflorescences, extension growth recommences via dormant, axillary buds, with the resulting mature growth unit appearing constricted at its point of attachment on the parent shoot. Because the aerial shoots of such plants have limited production of secondary conducting tissues, especially in species with photosynthetic stems, the vascular insertions remain narrow throughout. Such potential vascular constraints can be mitigated if the plant branches at its base, in which case each growth unit can root independently; but overall this strongly sympodial mode of construction seems to limit the stature of the plant as well as the degree of succulence each branch unit can attain. In contrast, shoots of succulent Euphorbia species that always bear cyathia in a lateral position are essentially free of these structural interruptions. Since these shoots can develop as comparatively more fully integrated entities over time, they are often able to reach larger dimensions, as exemplified by species that bear resemblance to barrel or columnar cacti (Fig. $2 \mathrm{~d}$ and $\mathrm{m}$ ), or attain tree stature as pencil plants.

Hence, the evolution of lateral inflorescences in xerophytic clades of Euphorbia likely facilitated the evolution of xerophytes of large stature. To our knowledge, all cactiform Euphorbia species that are $0.5 \mathrm{~m}$ or greater in height have lateral inflorescences, as do all arborescent pencil plants. These species are conspicuous and dominant elements (Fig. 2d) of many vegetation types occurring in arid regions of southern and eastern Africa and Madagascar, 
and the origins of these large xerophytes were undoubtedly important to the evolution of the distinctive ecological communities in which they occur. Diversity estimates reflect the significance of this pair of traits, indicating that approximately 600 of the 850 species of Euphorbia xerophytes have lateral inflorescences and furthermore that 400 of those species are also of large stature. This evidence suggests that the evolution of lateral inflorescences was a significant factor for the diversification of these xerophytes by enabling a novel ecological opportunity through a more effective succulent stem design.

4.2.2.1. Subgenus Esula. Of the four subgeneric clades, subgenus Esula is the least varied in terms of growth form and plant architectural diversity. The herbaceous habit is reconstructed as a synapomorphy for the subgenus and characterizes all members of the clade except for some Macaronesian and African species in subclades B3.1 and B3.2 (Figs. 3a and 4a). Whether herbaceous or not, all members of subgenus Esula have a similar basic unit of growth consisting of a leafy, orthotropic shoot that is usually unbranched below a terminal inflorescence, or the shoot is otherwise determinate (Figs. $1 \mathrm{j}$ and $2 \mathrm{~b}$ ). Shoot construction of this type is common in herbs generally, and fully describes the growth of the annual species in the subgenus. Perennial herbaceous species are similar but can produce many axes by basal branching. The few lineages in which persistent, aerial shoot systems are secondarily derived contain species that are shrubs to small trees or stem succulents of the pencil-plant type, as in E. mauritanica (Fig. 2f). This is best exemplified in the clade of section Aphyllis (clade inclusive of B3.1 and B3.2; Figs. 3a and 4a; Barres et al., 2011). Architectural analyses of several species belonging to these groups reveals that the aerially branched taxa all conform to Leeuwenberg's model (Hallé et al., 1978). This model represents one of the simplest approaches to tree building, because all branches are morphologically equivalent modules. Growth commences as outlined above in the herbaceous taxa, but then a series of branches is initiated in multiple planes below the inflorescence region that repeats the construction of the parent shoot. Subsequent branching proceeds in a similar fashion, but usually with a progressive decrease in shoot size. Mature individuals can thus become small trees with dense, rounded crowns (e.g., E. bourgaeana) or, if the epicotyledonary axis is relatively short, plants may be densely branched, pencil-plant shrubs (e.g., E. aphylla) to almost cushion-like shrubs (e.g., E. acanthothamnos). Xeromorphic growth forms evolved within subgenus Esula only in the section Aphyllis clade, where many species exemplify the pencil-plant growth form (E. aphylla and subclade B3.2; Figs. 3a and 4a; either with branched or unbranched aerial axes), and in E. dimorphocaulon, which develops a persistent, caudiciform stem that produces ephemeral flowering branches at the apex and stoloniferous shoots at the base (Radcliffe-Smith, 1982).

4.2.2.2. Subgenus Rhizanthium. Based on our observations in subgenus Rhizanthium, branching is characteristically sympodial, with terminal inflorescences, as in the woody members of subgenus Esula. Woodiness, however, is plesiomorphic for subgenus Rhizanthium. Several species, including the earliest-diverging lineage of $E$. antso, develop a leader shoot that enables the production of a morphologically distinct trunk (Rauh, 1998). Shoot dimorphism is also apparent in the production of lateral short shoots, which characterize many species formerly contained in sections Lyciopsis and Somalica, such as E. smithii and E. giumboensis (Carter, 1988b).

Clade A6, a major group of South African xerophytes, is of interest because it is the only species-rich radiation of succulent Euphorbia in which inflorescence position is variable, and for which the ancestral state for inflorescence position is terminal. Of the two subclades of this lineage supported by our data, succulents with terminal inflorescences are only present in subclade A6.2
(Figs. 3a and 4b). Terminal-flowering taxa of this lineage form a grade, of which the more cactiform members have squat stem modules that sometimes form linear sympodia with a strongly jointed appearance, or else branch basally. Other species in this assemblage develop elongated internodes and attain a pencil-plant physiognomy. The latter condition is best exemplified in E. drege$a n a$, in which stems can reach a height of over $1 \mathrm{~m}$ before flowering (Fig. 2e). Axes are essentially senescent after they flower, with subsequent shoots developed by basal branching. The convergence in form and architecture of $E$. dregeana with that of some pencilplants of the unrelated E. mauritanica species group (subclade B3.2, Fig. 2f) is so complete that it was recently suggested that they both be included in subgenus Esula (Bruyns et al., 2006).

The monophyletic, lateral-flowering group nested within subclade A6.2 (from E. bergeri to E. ramiglans) contains some of the most unusual-appearing succulent angiosperms, although they are generally cactiform in aspect. Among these are species such as E. flanaganii that exhibit the distinctive "medusoid" growth form (Fig. 2k). The disc-like apical region produces a mostly peripheral series of cylindrical, thornless first-order branches. In other species, such as E. schoenlandii, the primary axis is rarely branched and elongates vertically, becoming stout at maturity and bearing prominent, helically arranged tubercles. In this species, an elongate, sterile peduncle is produced at the apex of each tubercle and becomes a curved spine; only later does the much shorter, true inflorescence emerge between the spine and the tubercle (Fig. $2 \mathrm{~m}$ ).

Species in subclade A6.1 are uniformly cactiform and have evolved the restriction of inflorescences to a lateral position independently from subclade A6.2. Except in the clade of E. bubalina and $E$. clava, stem tubercles are organized into vertical rows, forming a series of ribs. The stems of these species can, therefore, appear pleated like those of many columnar cacti. The cactiform appearance of several species is enhanced by the production of sharp, axillary thorns derived from the persistent, indurated bases of inflorescence peduncles. Members of this clade do not reach the large size of many of the cactiform xerophytes in subgenus Euphorbia, but the stems of a few species in this group, such as E. pentagona, can attain heights of up to $3 \mathrm{~m}$ (White et al., 1941).

4.2.2.3. Subgenus Euphorbia. Among the four subgeneric clades, subgenus Euphorbia has the greatest diversity of growth forms and plant architecture and, correspondingly, exhibits the greatest complexity in the evolution of these traits. The ancestrally woody taxa sampled here exhibit relatively simple architectural approaches to tree building. For example, E. plumerioides and E. punicea (Bell, 1991) both conform to Leeuwenberg's model, and E. sinclairiana, an understory treelet of humid Neotropical forests, frequently remains single-stemmed. Although not well characterized architecturally, many of the largest arborescent members of the genus are close relatives to ancestrally woody species sampled here, including the Mexican E. tanquahuete, a tree of up to $25 \mathrm{~m}$ (Steinmann and Porter, 2002) and the Madagascan E. pirahazo, a tree of up to $30 \mathrm{~m}$ (Aubriot, 2008; E. mandravioky, Fig. 2a, is closely related).

The evolution of xeromorphic growth forms within subgenus Euphorbia is the most complex of the subgeneric clades. There are five independent origins of xeromorphic growth forms within subgenus Euphorbia, compared with two in subgenus Rhizanthium, and, overall, these also have greater structural complexity. The two origins of lateral inflorescences within the New World clade are associated with species-poor clades of well-branched pencil plants (Fig. 4c; E. sipolisii and E. weberbaueri) that superficially appear similar to some of the sympodially branched pencil plants previously discussed. Monopodial growth in pencil plants of subgenus Euphorbia makes possible different architectural strategies relative to nearly all of those of the other subgenera. Indeterminate 
meristems allow these plants to develop an extended trunk and become arborescent. This phenomenon is best exemplified in section Tirucalli (clade C3; Fig. 2g), which contains one of the primary radiations of pencil plants in Euphorbia. Cremers $(1977,1984)$ analyzed the architecture of many of the Madagascan species in this clade, which can become succulent trees up to $20 \mathrm{~m}$ in height, demonstrating that nearly all the arborescent species conform to architectural models characterized by the exclusive development of monopodial, orthotropic axes. Not all pencil plants in subgenus Euphorbia are monopodial, however. Sympodial pencil-plants are found in section Crepidaria, represented here by E. lomelii (Cacho et al., 2010) and in E. intisy (in an unnamed sister group to section Tirucalli; Cremers, 1977).

Clade C5 (Fig. 3b), which includes sections Euphorbia, Goniostema and Monadenium, is the most species-rich and morphologically diverse group of xeromorphs within Euphorbia and is also associated with a transition to lateral inflorescences, effecting monopodial growth. Members of sections Euphorbia and Goniostema, despite their close relationship, almost wholly contrast in their range of growth forms, whereas growth form diversity in section Monadenium has parallels with both of these clades.

The Madagascan section Goniostema (subclade C5.1, Fig. 3b) is the largest and most diverse radiation of caudiciform shrubs within Euphorbia (Figs. 2c and 4c). The stems of many species are little branched or unbranched aerially and often bear a pair of stipular spines at each node that can be accompanied by supernumerary spines (Uhlarz, 1974). Based on our sampling, phyllotaxy in the earliest-diverging lineage of the section (represented by $E$. neohumbertii + E. iharanae) is unusual because it emphasizes the vertical relationship among nodes so that stems are strongly angled and bear vertical rows of spines (Fig. $2 \mathrm{n}$ ). Despite the distinctiveness of this physiognomy, a more completely sampled phylogenetic study of this section suggests that it arose at least twice within the group (Haevermans et al., 2004). Pencil plants evolved once within the section in a lineage represented here by E. alluaudii (Haevermans et al., 2004). These pencil plants are distinctive in having axes that commence development as long shoots but abruptly differentiate to a short shoot-like morphology during the reproductive phase of growth. Growth remains monopodial, but the unusual development of these shoots is evidenced on older axes as a series of constrictions that bear circular scars (Fig. 2i; Cremers, 1977). This mode of shoot development is further emphasized in the lateral branches of $E$. hedyotoides and related species-close relatives of E. alluaudii-because long shoots differentiate permanently into short shoots. Each short shoot becomes sequentially displaced by a vigorous long shoot(s) that effects yearly extension growth, so that the resulting branch complexes are sympodia (Fig. $2 \mathrm{j}$ ). Therefore, the evolution of these architectural features in E. hedyotoides and allies makes possible the only known transition from monopodial growth to sympodial growth in Euphorbia.

Based on our analyses, the ancestral state for growth form at the root of section Monadenium (subclade C5.2, Fig. 4c) is also a caudiciform shrub. Included in this section is Euphorbia umbellata (formerly placed in Synadenium), which matures as a pachycaul tree. However, our sampling of this section is sparse ( 3 of about 90 species) given the extensive diversity of growth forms in this clade, such as unsampled cactiform succulents in E. ritchiei and vining caudiciforms in E. neorubella. Leaf succulence, uncommon and poorly expressed in Euphorbia as a whole, is best developed in some members of this clade.

Section Euphorbia (subclade C5.3, Fig. 3b) includes many of the best-known cactiform succulents within Euphorbia, and most of the large, candelabra-like species that merit comparison with columnar cacti (Fig. 2d). Stems are commonly tuberculate or ribbed and often bear a highly modified, sclerotic branch complex at each node termed a spine shield (Fig. 2o), which in its most basic condition bears a pair of spines said to be of stipular origin and terminates in an additional pair of spines, according to Uhlarz (1974). Substantial variation on this basic plan occurs within the clade (Carter, 1994).

Results from this and other molecular phylogenetic analyses (e.g., Zimmermann et al., 2010) indicate that the Socotran endemic E. abdelkuri-an apparently leafless, spineless, clustering, cactiform species-is sister to all other members of section Euphorbia, with most lineages diverging subsequent to this species containing cactiform representatives. The reconstructed growth form for the section, therefore, is a cactiform succulent (Fig. 4c).

The similarity in form between cactiform Euphorbia species and many Cactaceae is a remarkable example of convergence in plant evolution, and should be further investigated to this end. But, it is also necessary to appreciate the differences that exist between the two groups at a fundamental structural level and, moreover, to understand the evolutionary implications of these differences. For example, many cactiform lineages of section Euphorbia, unlike cacti, maintain the capability of developing large foliage leaves, potentially decreasing their dependence upon stem photosynthesis. From an evolutionary perspective, this phenomenon may have conferred a degree of lability within the clade that facilitated transitions to an array of growth forms in which leaves resume the primary role as photosynthetic organs. Such transitions rarely occur in Cactaceae (Edwards et al., 2005; Hernández-Hernández et al., 2011), but might not be uncommon in section Euphorbia. This is illustrated in our analyses by the strongly nested clade of E. unispina and $E$. venenifica, which have secondarily derived a relatively early onset of periderm production and become caudiciform treelets that bear large, deciduous foliage leaves (Fig. 4c). Euphorbia drupifera, a pachycaul tree, provides another example of such a transition. Other examples that await further investigation include several geophytic species from India (Aditya, 2010) and Africa (Gilbert, 1987) that resolve in strongly nested positions within section Euphorbia in other studies (Steinmann and Porter, 2002; Zimmermann et al., 2010).

4.2.2.4. Subgenus Chamaesyce. The reconstructed state for growth form at the root node of subgenus Chamaesyce is either a non-xeromorphic, woody plant in a majority of the phylogenetic trees examined, or else equivocal (Fig. 4c), with herbs and woody plants reconstructed with much higher proportional likelihoods than any of the xerophyte character states (results not shown). Stem succulence is, therefore, a derived condition and is most common in the early-diverging African/Madagascan lineages of this clade (e.g., $E$. platyclada), but is neither as common nor as strongly expressed here as in subgenus Euphorbia. Pencil plants are the most common xeromorphic growth form within subgenus Chamaesyce and have at least three independent origins within the clade. Those of the largely southern African section Articulofruticosae (clade D3, Fig. $3 \mathrm{~b}$ ) are unusual relative to almost all other pencil plant Euphorbia species in their decussate phyllotaxy and sometimes limited extent of succulence, so that some species of this clade consequently resemble species of Ephedra (Fig. 2h). Pencil plants also originated within the petaloid appendage clade (subclade D4.3, Fig. 2). The Brazilian E. appariciana (lineage D4.2) is unusual in that the succulent portion of its stem is entirely internodal because each branch unit terminates in a cyathium. Other pencil plant species not sampled in this study, such as the well-known candelilla, E. antisyphilitica, are resolved in other studies within section Alectoroctonum (i.e., subclade D4.6, Fig. 3b; Steinmann and Porter, 2002; Zimmermann et al., 2010).

The second largest assemblage of herbaceous Euphorbia species evolved in subgenus Chamaesyce, and these are mostly contained within the petaloid appendage clade (subclade D4.3, Fig. 3b). Our analyses reveal that there are several independent transitions back 
to a woody habit in the petaloid appendage clade, similar to the pattern we found in subgenus Esula (Fig. 4c). Unlike subgenus Esu$l a$, the secondarily woody lineages of clade D4 are architecturally diverse, perhaps related to the independence of their origins (based on information from four species in Hallé et al., 1978).

Phyllotaxy is a very labile trait in subgenus Chamaesyce, unlike the other subgenera of Euphorbia. Opposite or whorled phyllotaxy characterizes several lineages in this subgenus, with members of section Anisophyllum (subclade D4.3; Figs. 1k, 3b and 4c) being the best known of these groups, owing to both the size of the clade (around 350 species) and its nearly global distribution. The evolution of the distinctive architecture expressed by most members of this group has received considerable research attention because it appears quite disparate from most other Euphorbia species. As we discuss below, these growth traits might have a synergistic association with the origin of $\mathrm{C}_{4}$ photosynthesis in the group as well as a key role in enabling very short generation times that might facilitate the success of many species as weeds (Yang and Berry, 2008).

The earliest diverging lineage of this clade is the species-poor subsection Acutae, represented in our analysis by E. acuta (Mayfield, 1991; Yang and Berry, 2011). The three species of subsection Acutae are unlike the other, uniformly $\mathrm{C}_{4}$ members of section Anisophyllum in that one species expresses a $C_{3}$ photosynthetic pathway and the other two a $C_{2}$ photosynthetic pathway $\left(\mathrm{a}_{3}-\mathrm{C}_{4}\right.$ intermediate type; Webster et al., 1975; Sage et al., 2011). In E. acuta, all axes are orthotropic and appear unbranched aerially, with decussate phyllotaxy throughout. Each axis becomes highly modular after the onset of the reproductive phase and develops as a linear sympodium. Each module consists of a shoot that apically bears a pair of opposite leaves and terminates in an inflorescence. This method of branch development is similar to that present in E. appariciana, but importantly differs in that the axillary shoot that perpetuates the sympodium develops contemporaneously with the parent shoot (sylleptic branching). Therefore, each inflorescence matures in an apparently lateral position, and the entire axis appears as an integrated whole, without evident articulations. Branching can be considered cymose because the branches develop exclusively from the axils of leaves that are interpretable as prophylls.

Cymose branching is more prevalent in the shoot construction of members of the species-rich core clade of section Anisophyllum that is sister to subsection Acutae, in which the epicotyledonary axis aborts above the first pair of foliage leaves, so that aerial shoots develop from buds in axils of the cotyledons (Hayden, 1988; Hayden and Troyanskaya, 1998). These shoot systems are variously monochasially or dichasially branched, but differ from nearly all other Euphorbia species in being plagiotropic (dorsiventral) by successively reorienting growth modules about $90^{\circ}$ in an alternating right-left hand fashion so that phyllotaxy becomes distichous (Fig. 1k). Plagiotropic branches with a distichous leaf arrangement maximize the total leaf surface area directly exposed to sunlight. Given that species belonging to the core clade of section Anisophyllum are $\mathrm{C}_{4}$ plants that typically grow in habitats exposed to intense sunlight with high daytime temperatures, and that can experience drought (Simmons and Hayden, 1997), maximal whole-plant photosynthetic rates can be sustained with little risk of photorespiration. Therefore, in synergy with the stabilization of the $\mathrm{C}_{4}$ photosynthetic pathway in members of this clade, the evolution of this novel suite of growth traits can be interpreted as achieving a design optimum that potentially is adaptively beneficial in such environments. The unusually early onset of flowering in many species, facilitated by the rapid transition to cymose branching, enables remarkably short generation times relative to other Euphorbia species. Multiple, overlapping generations can be established within a growing season in the many annual herbaceous species, such as the ubiquitous weed E. maculata (Fig. $1 \mathrm{k}$; Suzuki and Teranishi, 2005). Furthermore, nearly all meristems forming branches (modules) are committed to flowering, which promotes sustained, increasingly high levels of reproductive output throughout the life of the plant (Suzuki and Ohnishi, 2006).

Although most species in section Anisophyllum are prostrate herbs, several species secondarily evolved woodiness. These species are usually small shrubs, but a few endemic to the Hawaiian Islands attain tree stature (Koutnik, 1987; Yang et al., 2009). The formation of erect axes in semi-woody to arborescent species may involve the development of reaction wood on the upper side of the leader shoot to reorient it vertically. Fisher and Stevenson (1981) demonstrated this growth phenomenon to be present in many trees constructed entirely from fundamentally plagiotropic axes.

The above discussion highlights the possible adaptive significance of morphological traits that characterize section Anisophyllum. Our synthesis suggests that it is probably not only the evolution of the $\mathrm{C}_{4}$ photosynthetic pathway within the group but also the acquisition of the full suite of novel structural traits that are biologically distinctive for the group that should be considered collectively as a possible "key innovation."

\subsection{Conclusions}

Based on our results and synthesis, it is clear that the evolution of the myriad growth forms in the genus was critical to its overall diversification. This perspective differs significantly from previous interpretations that emphasized the origin of the cyathium as the key innovation that led to the diversification of the genus. The origin of these novel growth forms permitted access to correspondingly novel ecological opportunities, and particularly impressive are the replicate radiations of similar growth forms in similar, mostly arid, environments among the subgeneric clades.

Although the tempo of evolutionary divergence within Euphorbia remains to be investigated in detail, branch length information (Suppl. Fig. S1) suggests that species-rich lineages might strongly differ in their relative rates of diversification. Extremely short branch lengths possibly indicate rapid radiations in both the southern African succulent clade within subgenus Rhizanthium and deep nodes of the New World clade of subgenus Euphorbia. In contrast, relatively moderate and even branch lengths throughout much of the clades of subgenus Esula could indicate a comparatively slower, steady accumulation of lineages through time. The marked differences in generation time and plant longevity associated with growth form (i.e., rapid and short-lived in members of Anisophyllum versus protracted and long-lived in most succulent lineages) may strongly influence substitution rate heterogeneity within Euphorbia, adding further complexity (Smith and Donoghue, 2008; Smith and Beaulieu, 2009). Future studies based on these concepts will be necessary to achieve a new evolutionary synthesis of this remarkable angiosperm clade.

\section{Acknowledgments}

The authors thank the following individuals and institutions for providing plant or DNA samples: T. Haevermans (P), D. Hannon (RSA, Huntington), Y. Yang and B. Dorsey $(\mathrm{MICH})$, Rolf Becker (PRE), J. Molero (BCN), UC Davis Botanical Conservatory, Huntington Botanical Gardens, International Euphorbia Society, FTG, K, $\mathrm{MICH}, \mathrm{MO}, \mathrm{NY}, \mathrm{RSA}$, US, and WAG. Support for this study came from a National Science Foundation PBI Grant (DEB 0616533) and the Smithsonian Institution.

\section{Appendix A. Supplementary material}

Supplementary data associated with this article can be found, in the online version, at doi:10.1016/j.ympev.2011.12.022. 


\section{References}

Aditya, S., 2010. A revision of geophytic Euphorbia species from India. Euphorbia World 6, 18-21.

Akaike, H., 1974. A new look at the statistical model identification. IEEE T. Automat. Contr. 19, 716-723.

Altekar, G., Dwarkadas, S., Huelsenbeck, J.P., Ronquist, F., 2004. Parallel Metropolis coupled Markov chain Monte Carlo for Bayesian phylogenetic inference. Bioinformatics 20, 407.

Aubriot, X., 2008. Systématique des euphorbes malgaches: Révision du groupe d'Euphorbia pachysantha. Master 1 de Systématique, Evolution et Paléontologie, Muséum National d'Histoire Naturelle, Paris, France.

Bally, P.R.O., 1961. The Genus Monadenium. Benteli, Berne.

Barres, L., Vilatersana, R., Molero, J., Susanna, A., Galbany-Casals, M., 2011. Molecular phylogeny of Euphorbia subg. Esula sect. Aphyllis (Euphorbiaceae) inferred from nrDNA and cpDNA markers with biogeographic insights. Taxon $60,705-720$.

Bell, A.D., 1991. Plant Form: An Illustrated Guide to Flowering Plant Morphology. Oxford University Press, Oxford, UK.

Benedí, C., Molero, J., Simon, J., Vicens, J., 1997. Euphorbia. In: Castroviejo, S., Aedo C., Benedí, C., Muñoz Garmendia, F., Nieto Feliner, G., Paiva, J. (Eds.), Flora Iberica: plantas vasculares de la Península Ibérica e Islas Baleares, vol. 8 Haloragaceae-Euphorbiaceae. Real Jardín Botánico, CSIC, Madrid, pp. 210-285.

Berg, R.Y., 1975. Myrmecochorous plants in Australia and their dispersal by ants. Aust. J. Bot. 23, 475-508.

Boissier, P.E., 1862. Euphorbiaceae, Euphorbieae. In: de Candolle, A. (Ed.) Prodromus systematis naturalis regni vegetalis, vol. 15. Masson and Son, Paris, pp. 1-188.

Bruyns, P.V., Mapaya, R.J., Hedderson, T., 2006. A new subgeneric classification of Euphorbia (Euphorbiaceae) based on ITS and psbA-trnH sequence data. Taxon 55, 397-420.

Cacho, N.I., Berry, P.E., Olsen, M.E., Steinmann, V.W., Baum, D.A., 2010. Are spurred cyathia a key innovation? Molecular systematics and trait evolution in the slipper spurges (Pedilanthus clade: Euphorbia, Euphorbiaceae). Am. J. Bot. 97, 493-510.

Carmichael, J.S., Selbo, S.M., 1999. Ovule, embryo sac, embryo, and endosperm development in leafy spurge (Euphorbia esula). Can. J. Bot. 77, 599-610.

Carter, S., 1985. New species and taxonomic changes in Euphorbia from East and Northeast tropical Africa and a new species from Oman. Kew Bull. 40, 809-825.

Carter, S., 1988a. Euphorbieae. In: Polhill, R.M. (Ed.), Flora of Tropical East Africa Euphorbiaceae (Part 2). A.A. Balkema, Rotterdam, pp. 409-564.

Carter, S., 1988b. Euphorbia section Somalica in Somalia. Euphorbia J. 5, 26-38.

Carter, S., 1994. A preliminary classification of Euphorbia subgenus Euphorbia. Ann. Missouri Bot. Gard. 81, 368-379.

Carter, S., Eggli, U., 2003. The CITES Checklist of Succulent Euphorbia Taxa (Euphorbiaceae), second ed. Federal Agency for Nature Conservation, Bonn.

Corner, E.J.H., 1976. The Seeds of Dicotyledons. Cambridge University Press, Cambridge, UK

Cremers, G., 1977. Architecture végétative de quelques espèces malagaches du genre Euphorbia L. Bull. Jard. Bot. Nat. Belg. 47, 55-81.

Cremers, G., 1984. Les euphorbes coralliformes de Madagascar. Bull. Jard. Bot. Nat. Belg. 54, 23-64.

Croizat, L., 1936. On the classification of Euphorbia. I. How important is the cyathium? Bull. Torrey Bot. Club 63, 525-531.

Croizat, L., 1937. On the classification of Euphorbia II. How should the cyathium be interpreted? Bull. Torrey Bot. Club 64, 523-536.

Dressler, R.L., 1957. The genus Pedilanthus (Euphorbiaceae). Contr. Gray Herb. 182, $1-188$.

Edwards, E.J., Nyffeler, R., Donoghue, M.J., 2005. Basal cactus phylogeny: implications of the Pereskia (Cactaceae) paraphyly for the transition to the cactus life form. Am. J. Bot. 92, 1177-1188.

Ehler, N., 1976. Mikromorphologie der Samenoberflächen der Gattung Euphorbia. Plant Syst. Evol. 126, 189-207.

Ehrenfeld, J., 1976. Reproductive biology of three species of Euphorbia subgenus Chamaesyce (Euphorbiaceae). Am. J. Bot. 63, 406-413.

Ehrenfeld, J.G., 1979. Pollination of three species of Euphorbia subgenus Chamaesyce, with special reference to bees. Am. Midl. Nat. 101, 87-98.

Espadaler, X., Gómez, C., 1997. Soil surface searching and transport of Euphorbia characias seeds. Acta Ecol. 18, 39-46.

Felsenstein, J., 1973. Maximum likelihood and minimum-steps methods for estimating evolutionary trees from data on discrete characters. Syst. Zool. 22, 240-249.

Felsenstein, J., 1985. Confidence limits on phylogenies: an approach using the bootstrap. Evolution 39, 783-791.

Fisher, J.B., Stevenson, J.W., 1981. Occurrence of reaction wood in branches of dicotyledons and its role in tree architecture. Bot. Gaz. 142, 82-95.

Forest, F., Chase, M.W., Persson, C., Crane, P.R., Hawkins, J.A., 2007. The role of biotic and abiotic factors in evolution of ant dispersal in the milkwort family (Polygalaceae). Evolution 61, 1675-1694.

Forster, P.I., 1994. Revision of Euphorbia plumerioides Teijsm. ex Hassk. (Euphorbiaceae) and allies. Austrobaileya 4, 227-246.

Frajman, B., Schönswetter, P., 2011. Giants and dwarfs: molecular phylogenies reveal multiple origins of annual spurges within Euphorbia subg. Esula. Mol Phylogenet. Evol. 61, 413-424.

Frodin, D., 2004. History and concepts of big plant genera. Taxon 53, 753-776.
Gilbert, M.G., 1987. Two new geophytic species of Euphorbia with comments on the subgeneric grouping of its African members. Kew Bull. 42, 231-244.

Gonzalez-Voyer, A., Fitzpatrick, J.L., Kolm, N., 2008. Sexual selection determines parental care patterns in cichlid fishes. Evolution 62, 2015-2026.

Govaerts, R., Frodin, D.G., Radcliffe-Smith, A., 2000. World checklist and bibliography of Euphorbiaceae (with Pandaceae), vol. 4. Royal Botanic Gardens, Kew, UK.

Haevermans, T., 2003. Le genre Euphorbia L. à Madagascar: phylogénie moléculaire et systématique. Thèse doctorale, Muséum National d'Histoire Naturelle, Paris, France.

Haevermans, T., Hoffmann, P., Lowry, P.P., Labat, J.-N., Randrianjohany, E., 2004. Phylogenetic analysis of the Madagascan Euphorbia subgenus Lacanthis based on ITS sequence data. Ann. Missouri Bot. Gard. 91, 247-259.

Haevermans, T., Labat, J.-N., 2004. A synoptic revision of the Malagasy endemic Euphorbia pervilleana group. Syst. Bot. 29, 118-124.

Hallé, F., Oldemann, R.A.A., Tomlinson, P.B., 1978. Tropical Trees and Forests: An Architectural Analysis. Springer, Berlin.

Hassall, D.C., 1977. The genus Euphorbia in Australia. Aust. J. Bot. 25, 429-453.

Hayden, W.J., 1988. Ontogeny of the cotyledonary region of Chamaesyce maculata (Euphorbiaceae). Am. J. Bot. 75, 1701-1713.

Hayden, W.J., Troyanskaya, O., 1998. Seedling development in species of Chamaesyce (Euphorbiaceae) with erect growth habits. Sida 18, 419-431.

Herbst, D., 1971. A new Euphorbia (Euphorbiaceae) from Hawaii. Pac. Sci. 25, 489490.

Hernández-Hernández, T., Hernández, H.M., Arturo De-Nova, J., Puente, R., Eguiarte, L.E., Magallón, S., 2011. Phylogenetic relationships and evolution of growth form in Cactaceae (Caryophyllales, Eudicotyledoneae). Am. J. Bot. 98, 44-61.

Holmes [Carter-Holmes], S., 1993. Euphorbiaceae, Euphorbia. In: Thulin, M. (Ed.), Flora of Somalia, vol. 1. Royal Botanic Gardens, Kew, pp. 306-337.

Hoppe, J.R., 1985. Die Morphogenese der Cyathiendrüsen und ihrer Anhänge, ihre blattypologische Deutung und Bedeutung. Bot. Jahrb. Syst. 105, 497-581.

Hoppe, J.R., Uhlarz, H., 1982. Morphogenese und typologische interpretation des Cyathiums von Euphorbia-Arten. Beitr. Biol. Pflanz. 56, 63-98.

Huelsenbeck, J.P., Ronquist, F., 2001. MrBayes: Bayesian inference of phylogenetic trees. Bioinformatics 17, 754-755, <http://mrbayes.csit.fsu.edu/>

Jordan, L.S., Jordan, J.L., Jordan, C.M., 1985. Changes induced by water on Euphorbia supina seed coat structures. Am. J. Bot. 72, 1530-1536.

Jordan, M.S., Hayden, W.J., 1992. A survey of mucilaginous testa in Chamaesyce. Collect. Bot. (Barcelona) 21, 79-89.

Kass, R.E., Raftery, A.E., 1995. Bayes factors. J. Am. Stat. Assoc. 90, 773-795.

Katoh, K., Kuma, K., Toh, H., Miyata, T., 2005. MAFFT version 5: improvement in accuracy of multiple sequence alignment. Nucl. Acids Res. 33, 511-518.

Kluge, A.G., 1989. A concern for evidence and a phylogenetic hypothesis for relationships among Epicrates (Boidae, Serpentes). Syst. Zool. 38, 7-25.

Koutnik, D.L., 1987. A taxonomic revision of the Hawaiian species of the genus Chamaesyce (Euphorbiaceae). Allertonia 6, 331-388.

Lengyel, S., Grove, A.D., Latimer, A.M., Majer, J.D., Dunn, R.R., 2009. Ants sow the seeds of global diversification in flowering plants. PLoS ONE, e5480. doi:10.1371/journal.pone.0005480.

Lengyel, S., Grove, A.D., Latimer, A.M., Majer, J.D., Dunn, R.R., 2010. Convergent evolution of seed dispersal by ants, and phylogeny and biogeography in flowering plants: a global survey. Perspect. Plant Ecol. Evol. Syst. 12, 43-55.

Lewis, P.O., 2001. A likelihood approach to estimating phylogeny from discrete morphological character data. Syst. Biol. 50, 913-925.

Maddison, W.P., Maddison, D.R., 2006. StocChar: a package of Mesquite modules for stochastic models of character evolution. Version 1.1.

Maddison, W.P., Maddison, D.R., 2010. Mesquite: a modular system for evolutionary analysis. Version 2.73. <http://mesquiteproject.org>.

Mauseth, J.D., 2004. The structure of photosynthetic succulent stems in plants other than cacti. Int. J. Plant Sci. 165, 1-9.

Mayfield, M.H., 1991. Euphorbia johnstonii (Euphorbiaceae), a new species from Tamaulipas, Mexico, with notes on the subsection Acutae. Sida 15, 573-579.

Molero, J., Garnatje, T., Rovira, A., Garcia-Jacas, N., Susanna, A., 2002. Karyological evolution and molecular phylogeny in Macaronesian dendroid spurges (Euphorbia subsect. Pachycladae). Plant Syst. Evol. 231, 109-132.

Molero, J., Rovira, A.-M., Vicens, J., 1996. Euphorbia L. sect. Cymatospermum (Prokh.) Prokh. (Euphorbiaceae) en la Península Ibérica. Morfología de las semillas. Precisiones taxonómicas y corológicas somber algunos táxones críticos. Ann. Jard. Bot. Madrid 54, 207-229.

Narbona, E., Arista, M., Ortiz, P.L., 2005. Explosive seed dispersal in two perennial Mediterranean Euphorbia species (Euphorbiaceae). Am. J. Bot. 92, 510-516.

Nylander, J.A.A., Wilgenbusch, J.C., Warren, D.L., Swofford, D.L., 2008. AWTY (are we there yet?): a system for graphical exploration of MCMC convergence in Bayesian phylogenetics. Bioinformatics 24, 581-583.

Pagel, M., 1994. Detecting correlated evolution on phylogenies: a general method for comparative analysis of discrete characters. Proc. Roy. Soc. Lond. B 225, $37-$ 45.

Pagel, M., 1997. Inferring evolutionary processes from phylogenies. Zool. Scr. 26, 331-348.

Pagel, M., 1999. The maximum likelihood approach to reconstructing ancestral character states of discrete characters on phylogenies. Syst. Biol. 48, 612-622.

Pagel, M., Lutzoni, F., 2002. Accounting for phylogenetic uncertainty in comparative studies of evolution and adaptation. In: Lässig, M., Valleriani, A. (Eds.), Biological Evolution and Statistical Physics. Springer, Berlin, pp. 148-161.

Pagel, M., Meade, A., 2006a. BayesTraits Version 1.0 (revised 10.02.10). <http:// www.evolution.rdg.ac.uk/BayesTraits.html>. 
Pagel, M., Meade, A., 2006b. Bayesian analysis of correlated evolution of discrete characters by reversible-jump Markov chain Monte Carlo. Am. Nat. 167, 808825

Pagel, M., Meade, A., Barker, D., 2004. Bayesian estimation of ancestral character states on phylogenies. Syst. Biol. 53, 673-684.

Park, K.-R., Jansen, R.K., 2007. A phylogeny of Euphorbieae subtribe Euphorbiinae (Euphorbiaceae) based on molecular data. J. Plant Biol. 50, 644-649.

Pemberton, R.W., 1988. Myrmecochory in the introduced range weed, leafy spurge (Euphorbia esula L.). Am. Midl. Nat. 119, 431-435.

Posada, D., Crandall, K.A., 1998. MODELTEST: testing the model of DNA substitution. Bioinformatics 14, 817-818, <http://darwin.uvigo.es/software/modeltest. html>.

Prenner, G., Cacho, N.I., Baum, D., Rudall, P.J., 2011. Is LEAFY a useful marker gene for the flower-inflorescence boundary in the Euphorbia cyathium? J. Exp. Bot. 62, 345-350.

Prenner, G., Hopper, S.D., Rudall, P.J., 2008. Pseudanthium development in Calycopeplus paucifolius, with particular reference to the evolution of the cyathium in Euphorbieae (Euphorbiaceae-Malpighiales). Aust. Syst. Bot. 21, 152-161.

Prenner, G., Rudall, P.J., 2007. Comparative ontogeny of the cyathium in Euphorbia (Euphorbiaceae) and its allies: exploring the organ-flower-inflorescence boundary. Am. J. Bot. 94, 1612-1629.

Prokhanov, Y.I., 1949. Genus 856. Euphorbia. In: Shishkin, B.K., Bobrov, E.G. (Eds.) Flora of the U.S.S.R, Gerniales, Sapindales, Rhamnales, vol. 14. Keter Press, Jerusalem, pp. 233-378.

Radcliffe-Smith, A., 1982. Euphorbia. In: Davis, P.H. (Ed.), Flora of Turkey and the East Aegean Islands, vol. 7. Edinburgh University Press, Edinburgh, pp. 571-630.

Rambaut, A., 1996-2002. Se-Al: sequence alignment editor ver. 2.0. <http:// tree.bio.ed.ac.uk/software/>.

Rambaut, A., Charleston, M., 2002. TreeEdit. Phylogenetic tree editor, ver. 1.0 alpha 10. <http://tree.bio.ed.ac.uk/software/treeedit/>.

Rambaut A., Drummond, A.J., 2003-2007. Tracer ver. 1.5. MCMC trace analysis package. <http://tree.bio.ed.ac.uk/software/>.

Rauh, W., 1995. The Succulent and Xerophytic Plants of Madagascar, vol. 1. Strawberry Press, Mill Valley, California.

Rauh, W., 1996. Euphorbia pachysantha Baillon, a remarkable and little-known arborescent Euphorbia from Madagascar. Cactus Succul. J. USA 68, 35-39.

Rauh, W., 1998. The Succulent and Xerophytic Plants of Madagascar, vol. 2. Strawberry Press, Mill Valley, California.

Reeves, J.H., 1992. Heterogeneity in the substitution process of amino acid sites of proteins coded for by mitochondrial DNA. J. Mol. Evol. 35, 17-31.

Ritz, C.M., Zimmermann, N.F.A., Hellwig, F.H., 2003. Phylogeny of subsect. Meleuphorbia (A. Berger) Pax \& Hoffm. (Euphorbia L.) reflects the climatic regime of South Africa. Plant Syst. Evol. 241, 245-259.

Sage, T.L., Sage, R.F., Vogan, P.J., Rahman, B., Johnson, D.C., Oakley, J.C., Heckel, M.A., 2011. The occurrence of $C_{2}$ photosynthesis in Euphorbia subgenus Chamaesyce (Euphorbiaceae). Exp. Bot. 62, 3183-3195.

Salisbury, B.A., Kim, J., 2001. Ancestral state estimation and taxon sampling density. Syst. Biol. 50, 557-564.

Sanderson, M.J., 1997. A non-parametric approach to estimating divergence times in the absence of rate constancy. Mol. Biol. Evol. 14, 1218-1231.

Schulter, D., Price, T., Mooers, A.O., Ludwig, D., 1997. Likelihood of ancestor states in adaptive radiation. Evolution 51, 1699-1711.

Scotland, R.W., 2010. Deep homology: a view from systematics. BioEssays 32, 438449.

Sernander, R., 1906. Entwurf einer monographie der europäischen Myrmekochoren. K. Sven. Vetenskapsakad. Handl. 41, 1-410.

Shimodaira, H., 2002. An approximately unbiased test of phylogenetic tree selection. Syst. Biol. 51, 492-508.

Shimodaira, H., 2004. Approximately unbiased tests of regions using multistepmultiscale bootstrap resampling. Ann. Stat. 32, 2616-2641.

Shimodaira, H., Hasegawa, M., 2001. CONSEL: for assessing the confidence of phylogenetic tree selection. Bioinformatics 17, 1246-1247, <http://www.is. titech.ac.jp/ shimo/prog/consel/>.

Simmons, M.P., 2004. Independence of alignment and tree search. Mol. Phylogenet. Evol. 31, 874-879.

Simmons, M.P., Hayden, W.J., 1997. Revision of the cerrado hemicryptophytic Chamaesyce of Boissier's "Pleiadeniae" (Euphorbiaceae). Brittonia 49, 155-180.

Smith, S.A., Beaulieu, J.M., 2009. Life history influences rates of climatic niche evolution in flowering plants. Proc. Roy. Soc. B 276, 4345-4352.

Smith, S.A., Donoghue, M.J., 2008. Rates of molecular evolution are linked to life history in flowering plants. Science $322,86-89$.

Steinmann, V.W., 2001. The Evolution of Succulence in the New World Species of Euphorbia (Euphorbiaceae). Claremont University, Claremont, California, Doctoral Dissertation.

Steinmann, V.W., 2003. The submersion of Pedilanthus into Euphorbia (Euphorbiaceae). Acta Bot. Mex. 65, 45-50.

Steinmann, V.W., Porter, J.M., 2002. Phylogenetic relationships in Euphorbieae (Euphorbiaceae) based on ITS and $n d h F$ sequence data. Ann. Missouri Bot. Gard. 89, 453-490.

Steinmann, V.W., van Ee, B., Berry, P.E., Gutiérrez, J., 2007. The systematic position of Cubanthus and other shrubby endemic species of Euphorbia (Euphorbiaceae) in Cuba. Ann. Jard. Bot. Madrid 64, 123-133.
Suzuki, N., Ohnishi, Y., 2006. Significance of the simultaneous growth of vegetative and reproductive organs in the prostrate annual Chamaesyce maculata (L.) Small (Euphorbiaceae). Ecol. Res. 21, 91-99.

Suzuki, N., Teranishi, S., 2005. Phenology and life cycle of the annual Chamaesyce maculata (L.) Small (Euphorbiaceae), with multiple overlapping generations in Japan. Ecol. Res. 20, 425-432.

Swofford, D.L., 2002. PAUP*: Phylogenetic Analysis using Parsimony (*and other methods). Ver. 4. Sinauer, Sunderland, Massachusetts, USA.

Tokuoka, T., 2007. Molecular phylogenetic analysis of Euphorbiaceae sensu stricto based on plastid and nuclear DNA sequences and ovule and seed character evolution. J. Plant Res. 120, 511-522.

Tokuoka, T., Tobe, H., 2002. Ovules and seeds in Euphorbioideae (Euphorbiaceae): structure and systematic implications. J. Plant Res. 115, 361-374.

Trumpke, H., 1914. Beträge zur Anatomie der sukkulenten Euphorbien. Buchdruckerei der Schlesischen Volkszeitung, Breslau.

Uhlarz, H., 1974. Entwicklungsgeschichtliche Untersuchungen zur Morphologie de basalen Blatteffigurationen sukkulenter Euphorbien aus den Subsektionen Diacanthium Boiss. und Goniostema Baill. Trop. Subtrop. Pflanzenwelt 9, 575639.

van der Pijl, L., 1982. Principles of Dispersal in Higher Plants. Springer-Verlag, Berlin, Germany.

van Ee, B.W., Berry, P.E., Riina, R., Gutiérrez Amaro, J.E., 2008. Molecular phylogenetics and biogeography of the Caribbean-centered Croton subgenus Moacroton (Euphorbiaceae s.s.). Bot. Rev. 74, 132-165.

Venkata Rao, C., 1971. Anatomy of the inflorescence of some Euphorbiaceae with a discussion on the phylogeny and evolution of the inflorescence including the cyathium. Bot. Notiser 124, 39-64.

Vindt, J., 1953. Monographie des euphorbiacées du Maroc. Première partie. Revision et systématique. Trav. Inst. Sci. Chérifien, Sér. Bot. 6, 1-219.

Vindt, J., 1960. Monographie des euphorbiacées du Maroc. Deuxième partie. Anatomie. Trav. Inst. Sci. Chérifien, Sér. Bot. 19, 220-533.

Vogel, S., 1954. Blütenbiologische Typen als Elemente der Sippengliederung dargesteelt anhand der Flora Südafrikas. Bot. Stud. 1, 1-338.

Webster, G.L., 1967. The genera of Euphorbiaceae in the southeastern United States. J. Arnold Arb. 48, 303-361, 363-430.

Webster, G.L., 1994. Synopsis of the genera and suprageneric taxa of Euphorbiaceae. Ann. Missouri Bot. Gard. 81, 33-144.

Webster, G.L., Brown, W.V., Smith, B.N., 1975. Systematics of photosynthetic carbon fixation pathways in Euphorbia. Taxon 24, 27-33.

Webster, G.L., Rupert, E., Koutnik, D., 1982. Systematic significance of pollen nuclear number in Euphorbiaceae, tribe Euphorbieae. Am. J. Bot. 69, 407-415.

Wheeler, L.C., 1943. The genera of living Euphorbieae. Am. Midl. Nat. 30, 456-503.

White, A., Dyer, R.A., Sloane, B.L., 1941. The succulent Euphorbieae (Southern Africa), vols. 1-2. Abbey Garden Press, Pasadena, California.

Wilgenbusch, J.C., Warren, D.L., Swofford, D.L., 2004. AWTY: a system for graphical exploration of MCMC convergence in Bayesian phylogenetic inference. <http:// ceb.csit.fsu.edu/awty>.

Wurdack, K.J., Davis, C.C., 2009. Malpighiales phylogenetics: gaining ground on one of the most recalcitrant clades in the angiosperm tree of life. Am. J. Bot. 96, 1551-1570.

Wurdack, K.J., Hoffmann, P., Chase, M.W., 2005. Molecular phylogenetic analysis of uniovulate Euphorbiaceae (Euphorbiaceae sensu stricto) using plastid $r b c L$ and trnL-F sequences. Am. J. Bot. 92, 1397-1420.

Wurdack, K.J., Hoffmann, P., Samuel, R., de Bruijn, A., van der Bank, M., Chase, M.W. 2004. Molecular phylogenetic analysis of Phyllanthaceae (Phyllanthoideae pro parte, Euphorbiaceae sensu lato) using plastid $r b c L$ DNA sequences. Am. J. Bot 91, 1882-1900.

Yang, Y., Berry, P.E., 2008. Abstract 347. Evolution of weediness in the Chamaesyce clade of Euphorbia s.l. (Euphorbiaceae)-biogeography, shift to early onset of reproductive growth, and opportunistic life-history strategies. Botany 2008 Vancouver, BC. <http://www.2008.botanyconference.org/engine/search/index. php? func=detail\&aid=347>

Yang, Y., Berry, P.E., 2011. Phylogenetics of the Chamaesyce clade (Euphorbia Euphorbiaceae): reticulate evolution and long-distance dispersal in a prominent $\mathrm{C}_{4}$ lineage. Am. J. Bot. 98, 1486-1503.

Yang, Y., Morden, C.W., Sack, L., Sporck, M.J., Berry, P.E., 2009. Abstract 861. Phylogeny and adaptive radiation of woody Hawaiian Chamaesyce from herbaceous and annual ancestors in subtropical North America (EuphorbiaEuphorbiaceae). Botany and Mycology 2009, Snowbird, UT. <http:// 2009. botanyconference.org/engine/search/index.php? func=detail\&aid $=861>$.

Yang, Z., 1993. Maximum-likelihood estimation of phylogeny from DNA sequences when substitution rates differ over sites. Mol. Biol. Evol. 10, 1396-1401.

Yang, Z., Rannala, B., 1997. Bayesian phylogenetic inference using DNA sequences: a Markov Chain Monte Carlo method. Mol. Biol. Evol. 14, 717-724.

Zimmermann, N.F.A., Ritz, C.M., Hellwig, F.H., 2010. Further support for the phylogenetic relationships within Euphorbia L. (Euphorbiaceae) from nrITS and trnL-trnF IGS sequence data. Plant Syst. Evol. 286, 39-58.

Zwickl, D.J., 2006. Genetic algorithm approaches for the phylogenetic analysis of large biological sequence datasets under the maximum likelihood criterion. Ph.D. dissertation, University of Texas at Austin, Austin, Texas. <https:// www.nescent.org/wg_garli/Main_Page> 